\title{
EL PRINCIPIO DE OFENSIVIDAD Y SU RELACIÓN CON LOS DELITOS DE PELIGRO ABSTRACTO EN LA EXPERIENCIA ITALIANA Y CHILENA. UN BREVE ESTUDIO COMPARADO*
}

\section{Carlos Cabezas Cabezas**}

RESUMEN: El presente trabajo tiene por objeto exponer, en términos de derecho comparado, el desarrollo de la, así denominada, teoría de ofensividad o lesividad en las experiencias italiana y chilena, tanto en la doctrina como en la jurisprudencia constitucional. Ello, pues a pesar que la teoría de la constitucionalización del bien jurídico o teoría de la ofensividad penal, desarrollada en la segunda mitad del siglo XX por la doctrina italiana, poseía una importante fuerza conceptual, ha demostrado serias dificultades en ser adoptado por la justicia de legitimidad de dicho país. Al mismo tiempo, en Chile, si bien con rasgos marcadamente diversos, la teoría de la necesaria lesión o puesta en peligro de un bien jurídico ha tenido una pequeña pero relevante acogida en el Tribunal Constitucional, acercando los resultados obtenidos a la experiencia italiana.

PALABRAS CLAVE: Principio de ofensividad - principio de lesividad control constitucional - delitos de peligro abstracto - Italia - Chile.

\section{OFFENSIVENESS PRINCIPLE AND ITS RELATION TO THE ABSTRACT CRIMES OF DANGER IN THE ITALIAN AND CHILEAN EXPERIENCE. A BRIEF COMPARATIVE STUDY}

ABSTRACT: This paper analyses, in terms of comparative law, the development of the so-called, offensiveness theory related to the

\footnotetext{
* $\quad$ El presente trabajo fue realizado en el marco del Proyecto de investigación POA 2009 de la Facultad de Ciencias Jurídicas de la Universidad de Antofagasta. Agradezco muy especialmente al responsable del proyecto, Pr. Dr. Patricio Lazo González.

Fecha de recepción: 11 de julio de 2012.

Fecha de aceptación: 30 de abril de 2013.

** Abogado, Magíster (Ll.Mg) en Derecho Penal y Procesal Penal de la Universidad de Antofagasta. Doctorando de la Universidad de Trento, Italia. Profesor de Derecho Penal, Universidad de Antofagasta. Correo electrónico: ccabezasc@gmail.com
} 
Italian and Chilean experiences, both in doctrine and in constitutional jurisprudence. This, because although the theory of constitutionalization of the legal or criminal offensiveness theory, developed in the second half of the twentieth century by the Italian doctrine, it had a strong conceptual force that it has shown serious difficulties in being adopted by the righteousness of legitimacy of that country. Meanwhile, in Chile, although with markedly different characteristics, the theory of the necessary injury of a legal right, it has had a small but significant acceptance in the Constitutional Court getting closer to the results to the Italian experience.

KEY WORDS: Principle of offensiveness - harmfulness principle constitutional control - abstract danger offenses - Italy - Chile.

\section{1) INTRODUCCIÓN: IMPORTANCIA DEL ESTUDIO}

El principio de ofensividad o lesividad, como se le conoce más exactamente en Chile, es utilizado ampliamente (aunque para diversos fines y con distintas intensidades) por la doctrina penal contemporánea. En efecto, cuando no se reconoce su valor como principio fundante del derecho penal -es decir, la idea que la función del derecho penal es la protección de bienes jurídicos- se le concede, al menos, una importante función legitimadora y limitadora del ius puniendi estatal.

Si bien el origen de dicha teoría puede rastrearse -con importantes antecedentes- en la obra de Birnbaum, la teoría de la ofensividad ha sido, en sus extremos más originales, un producto propio de la ciencia penal italiana de la segunda mitad del siglo XX ${ }^{1}$. Sus representantes más importantes buscaron en el citado principio una auténtica clave del sistema que permitiese no solo interpretar los tipos penales ya existentes -función que por lo demás ya había prefijado Arturo Rocco en los albores del Código Penal de 1930-, sino como principio de fuerte impacto en la actividad legislativa y, especialmente, en el trabajo de la Corte Constitucional.

El presente trabajo pretende exponer en sus líneas más relevantes el desarrollo de la teoría de la ofensividad o constitucionalización del bien jurídico como se le ha venido denominando en Italia, tanto en la doctrina como en la jurisprudencia constitucional y comparar algunos de sus resultados con la experiencia chilena. Resulta interesante este ejercicio dado

Manes, Vittorio (2005) Il principio di offensività nel diritto penale, Torino: Giappichelli, 2005, pp. 1 y 76. SAlcuni, Giandomenico (2007). "Esiguità e reati di pericolo astratto: intorno all'applicabilità dell'art. 34 D.LG. N. 274 del 2000 al reato di guida in stato di ebbrezza". Cassazione penale, n. 07/08, 2901-2911, p. 2902; Donini, Massimo (2004) Il volto attuale dellillecito penale, Milano: Giuffrè, 2004, p. 91. 
que, a pesar que ambos ordenamientos penales no pertenecen a la misma época ni, necesariamente, a la misma tradición jurídica, comparten similares puntos de contacto, como por ejemplo el carácter eminentemente realístico (oggettivistico) que refleja cierta concepción de la persona y sus relaciones con el Estado ${ }^{2}$. Por otro lado, la aún breve jurisprudencia del Tribunal Constitucional chileno se ha pronunciado, directa o indirectamente en un par de ocasiones acerca de la ofensividad o lesividad de ciertos tipos penales. La Corte Constitucional italiana lo ha hecho en varias ocasiones, y con un aparato conceptual diverso y, sin embargo, algunos resultados son muy similares a los de su homóloga chilena. Por ello, consideramos que un estudio comparado puede resultar útil con el objeto de contribuir al debate sobre este principio, al cual todos asignan importancia, pero que, debido a la mutabilidad de sus posibles contenidos resulta algo impredecible en su aplicación práctica.

\section{2) EL PRINCIPIO DE OFENSIVIDAD EN LA EXPERIENCIA ITALIANA Y CHILENA}

\section{1) EL PRINCIPIO DE OFENSIVIDAD EN EL SISTEMA ITALIANO}

\subsection{1) La teoría de la constitucionalización del principio de ofensividad}

El principio de ofensividad dice relación con que una conducta, para ser considerada punible, debe, además de cumplir los restantes requisitos de la teoría del delito (acto humano, típico culpable), ocasionar una lesión o puesta en peligro de un bien jurídico de cierta relevancia ${ }^{3}$. Desde esta perspectiva, el citado principio gira en torno a dos nociones capitales en

2 Por cierto, sería desproporcionado atribuir al origen de ambos códigos la misma matriz liberal, dado que es sobradamente sabido que el Código del 30 fue el Código del fascismo; sin embargo, como lo reiteran y recuerdan varios autores, el citado Código es el resultado de un compromiso entre las posiciones propias del positivismo iliberal y la ciencia penal italiana iluminista previa. Ver, por todos, Rosoni, Isabella (2006) "Dalle codificazione preunitarie al códice Rocco”, en Insolera G, Mazzacuva N., Pavarini, M., Zanotti., M. Introduzione al sistema penale. Terza edizione. Torino: Giappichelli, pp. 3-31, p. 23 ss.

3 De hecho, la teoría del bien jurídico suele explicarse y estudiarse en el apartado relativo a la antijuridicidad o injusto o al tratar el problema del desvalor de resultado. En otros casos, su estudio tiene lugar a propósito de la tipicidad, precisamente, en relación al resultado. Por último, una parte de la manualística lo reserva a la parte relativa a los principios (constitucionales o no) del derecho penal. 
la doctrina penal moderna: el concepto de bien jurídico ${ }^{4}$ y el concepto de ofensa ${ }^{5}$.

La doctrina italiana, hasta mediados de los años 60 había relacionado preponderantemente estas ideas al concepto de materialidad del delito y asignaba al concepto de bien jurídico, siguiendo tanto la doctrina extranjera como la obra de Rocco, un valor importante en sede de interpretación del tipo, negándole, o al menos no asignándole expresamente, función crítica, en consonancia con la autoritaria ideología subyacente al así denominado, indirizzo técnico-giuridico ${ }^{6}$. Esta situación cambia radicalmente (aunque con antecedentes relevantes ${ }^{7}$ ) con la elaboración de la Teoría de la constitucionalización del principio de ofensividad, obra de Franco Bricola y de sus discípulos ${ }^{8}$. La clave para entender el nuevo sig-

4 En la doctrina italiana, menos permeable en esta materia a teorías de allende los Alpes, se entiende bastante pacíficamente que una de las funciones del derecho penal es precisamente la protección de bienes jurídicos. Véase, por todos, Mazzacuva, Nicola (2006), "Diritto penale e costituzione”, en Insolera G., Mazzacuva N., Pavarini, M., Zanotti., M. Introduzione al sistema penale. Terza edizione. Torino: Giappichelli, pp 83-125, p. 96.

5 En términos de operatividad del principio, Angioni, Francesco (1983). Contenuto e funzione del concetto di bene giuridico, Milano: Giuffrè, p. 7: "Con respecto al importante problema de la medida de la tutela o de la ofensa, va subrayado que establecer cuál es la extensión, el objeto de la ofensa es de fundamental importancia por dos razones claves: en primer lugar, para saber si el hecho ofensivo es de lesión, de peligro u otra cosa; o sea, que indica, con referencia al problema del grado de anticipación de la tutela realmente dispuesto con el tipo (perspectiva dogmática) o del grado de anticipación jurídicamente admisible (perspectiva crítica inmanente), o políticamente oportuna (perspectiva político-criminal)"

6 Acerca de esta escuela, en especial respecto de la función del bien jurídico en su sistemática, se reenvía a la obra de Rocco, Arturo (1913) L'oggetto del reato e della tutela giuridica penale. Contributo alle teorie generali del reato e della tutela giuridica penale. Contributo alle teorie generali del reato e della pena. Torino: F.lli Bocca. Como se sabe, la teoría del maestro italiano distinguía entre el objeto jurídico sustancial genérico y sustancial específico. Este último, reconducible al concepto moderno de bien jurídico tiende a coincidir con la valoración ya efectuada por el legislador en la norma (frente al deseo de los partidarios de esta escuela de despojar la teoría del delito de cualquier elemento metajurídico - en este caso, de conceptos sociológicos). Pues bien, realizado esto, es fácil advertir cómo el bien jurídico pierde cualquier capacidad crítica o limitativa, terminando por validar cualquier elección del legislador. En este sentido, Fiandaca, Giovanni; Musco, Enzo (2001) Diritto penale, parte generale. Quarta edizione, Bologna: Zanichelli, p. 9; Rosoni (2006) 25.

7 Son antecedentes del renovado interés por una visión del bien jurídico en sentido crítico, entre otros, Bettiol, Giuseppe (1995). El problema penal. Traducción de José Luis Guzmán Dalbora. Buenos Aires: Hammurabi, p. 125 y siguientes, donde el profesor padovano, el cual centra el sistema del derecho penal en la idea de valor, concibe al bien jurídico como "la expresión penal corriente del valor" y la idea de bien jurídico como idea angular de todo el derecho penal, como expresión del fin al que la norma tiende. Otro antecedente es la concepción del delito bajo el prisma del nullum crimen sine iniuria, que rastrea sus antecedentes en el proceso de laicización del derecho penal y que se expresa habitualmente bajo la idea de "dañosidad social"; estos dos conceptos representan "la base cultural sobre la cual ha sido edificada la teoría de la ofensividad y, todavía antes, constituyen el fermento sobre la cual se ha levantado la misma teoría que identifica el delito como <<ofensa a bienes jurídicos $>>$, como epifanía de la <<idea de fin>>". Manes (2005) 59.

8 El origen de la teoría, como es fácil entender, se radicaba en el temor de una legislación de mayorías sin ningún tipo de freno inhibitorio. Véase Valenti, Alessandro (2006) "Principi 
nificado que asume la teoría está, como su nombre lo indica, en un fuerte ligamen con la Constitución, en el entendido que la ofensividad derivaba directamente del mandato de la Carta Fundamental de 1948: de este modo, por una lado, el legislador solo debía convertir en delito conductas que ofendiesen bienes jurídicos explícita o implícitamente reconocidos por la Constitución y solo respecto de aquellas conductas que significasen lesiones o puestas en peligro -es decir, ofensivas- de dichos bienes jurídicos. A ello debía agregarse que el principio funcionaba, por así decirlo en dos momentos y dirigido a dos personas distintas: por un lado, se dirigía al legislador como una fuerte limitación de sus prerrogativas y facultades a la hora de legislar, pues se encontraba, de algún modo, atado de manos a la hora de elegir intereses y formas de lesión para transformarlas en delito; y luego al juez, sobre todo al constitucional, pues le entregaba una herramienta con un sólido anclaje en el texto fundamental para declarar inconstitucionales aquellos preceptos que no reuniesen las características de una ofensividad constitucionalmente construida.

La teoría del maestro de Bologna se basaba en la reinterpretación de los mandatos constitucionales de protección privilegiada de la libertad personal y del realismo a la hora de determinar qué debía entenderse por delito 9 en el sentido que la restricción de la libertad personal -bien supremo en el ordenamiento constitucional- por parte del Estado solo estaría justificada si con ello se intentase tutelar no cualquier interés más o menos difuso en el tejido social a través de cualquier tipo de afectación, sino un bien directamente protegido por la norma suprema del ordenamiento y por medio de conductas que realísticamente (es decir: en la realidad factual) lesionasen (menoscabasen, destruyesen) o pusieren en

di materialità e offensività", en Insolera G, Mazzacuva N., Pavarini, M., Zanotti., M. Introduzione al sistema penale. Terza edizione. Torino: Giappichelli, pp. 274-312.

9 Es imposible sintetizar en pocas palabras los pasos más importantes de esta concepción. Con todo, esta se desarrolla sobre los siguientes ejes: la rigidez de la Constitución italiana, la relevancia de las normas constitucionales en materia penal y la prevalencia de la libertad personal como bien supremo del ordenamiento jurídico, así como establece la propia Carta Fundamental (pp. 561-570). Las consecuencias de dicha concepción son fundamentalmente dos: en sede de formación de la norma el legislador "además de no poder incriminar hechos que se concreten en el ejercicio de un derecho constitucional (...) no puede adoptar la sanción penal por hechos lesivos de valores que, sin ser antagónicos a la Constitución, no encuentran en ella algún reconocimiento explícito”, es decir, un límite negativo (p. 572). La segunda consecuencia dice relación con la interpretación de la norma: "Esto significa que la máxima restricción de la libertad personal, que es aquella que opera efectiva o potencialmente a través de la sanción penal, no puede realizarse sino como extrema ratio. Para precisar este concepto, que es de ya vieja adquisición, puede afirmarse hoy, con una mayor consciencia constitucional, que la sanción penal puede ser adoptada solo en presencia de la violación de un bien, el cual, aun no de igual grado que el valor (libertad personal) sacrificado, esté al menos dotado de relevancia constitucional" (p. 565). Véase en particular BricoLA, Franco (1997) “Teoría generale del reato”, en Canestrari, S. y Melchionda, A: Scritti di diritto penale. Milano: Giuffrè, vol. 1, pp. 539-820, p. 561 y ss. 
peligro (concreto) dichos bienes de relevancia constitucional. Con ello, la necesaria lesión de bienes jurídicos, como principio, pasaba de un mero enunciado de matriz ius naturalista a un principio de derecho positivo ${ }^{10}$ que, junto con otros, también descendientes de la Constitución republicana, tenía de frente la dura tarea de despejar el Código autoritario del 30 de aquellos tipos penales que mal convivían con el liberalismo imperante con posterioridad al término de la Segunda Guerra Mundial. De esta manera, es evidente que lo que pretendía la teoría de la constitucionalización del bien jurídico y el principio de ofensividad era asignar una importante misión a la Corte Constitucional, último garante de las libertades individuales de frente al legislador democrático.

El contenido crítico del bien jurídico constitucionalizado se orientaba, así, a desterrar, en base a esta repotenciación del principio realístico, las presunciones de responsabilidad, no solo aquellas que decían relación con cuestiones subjetivas conectadas a la personalidad del autor (bastante abundantes por lo demás en el Código del 30), sino también aquellas que suponían presunciones de lesión o puesta en peligro. En la mira, por tanto, se hallaban, sobre todo, los delitos de peligro abstracto o presunto que suponen, según la conceptualización tradicional, una presunción de derecho acerca de la potencialidad lesiva de ciertas conductas, impidiendo al juez su verificación caso a caso ${ }^{11}$. A ello se sumaban las figuras típicas que careciesen de un bien jurídico reconducible a la Constitución, por ejemplo, aquellos delitos que castigasen exclusivamente cuestiones relativas a la moral sexual o la falta de sentimientos que se reputasen indignos de relevancia constitucional.

A pesar del éxito de la teoría y la sucesiva adopción de esta -aunque con declinaciones diferentes- por parte de varios autores, ella, obviamente, no quedó exenta de críticas. Las más relevantes, por cierto, tenían que ver con la primera parte de ella, es decir, la teoría del bien jurídico constitucionalizado $^{12}$. Por una parte se indica que resulta dudoso que la Constitución prevea efectivamente bienes y, aun sí fuese así, significaría una limitación inaceptable al legislador al imponer, una vez y para siempre,

\footnotetext{
En el mismo sentido, Angioni (1983) 153.

Véase apartado 3.3.1.

Expone las complejidades de un examen como el propuesto Donini, Masimo (1996) Teoria generale del reato. Una Introduzione, Padova: Cedam, 1996, p. 147, especialmente cuando se trata de bienes jurídicos y la tutela es demasiado anticipada y formalizada. En sentido similar, pero entregando elementos de juicio para su determinación, Fiandaca, Giovanni (1984), "La tipicizzazione del pericolo". Dei delitti e delle pene (3), 441-472, p. 442, y Grasso, Giovanni (1986), "L'anticipazione della tutela penale; i reati di pericolo e i reati di attentato". Rivista italiana di diritto e procedura penale (3), 689-728, p. 705, ambos considerando la importancia del bien como fundamento o prohibición de anticipación de la tutela. En sentido crítico, aunque reconociendo su utilidad, Pulitanò, Domenico (1976). L'errore di diritto nella teoría del reato, Milano: Giuffrè, p. 104.
} 
un conjunto de valores que iría a colisionar directamente con el principio democrático de separación de funciones ${ }^{13}$, además de la ambigüedad y vaguedad de los posibles intereses en ella estipulados ${ }^{14}$. El mismo autor de la teoría, ya en su versión original, se encargaba de aclarar que no se trataba, en absoluto, de un catálogo cerrado, pues también se consideraban bienes jurídicos de rango constitucional aquellos que implícitamente pudiesen remitirse a ella; pero, con ello, se debe convenir que la teoría pierde buena parte de su fuerza vinculante, que era su mayor mérito, pues de este modo terminaba por convertirse en una "exclusiva prerrogativa de la política criminal" 15 , el cual a través de un mero ejercicio argumentativo, podía convertir cualquier interés en constitucional, rastreando su fundamento en la Carta del 48; es decir, a fin de cuentas, regresando al poder político, reduciéndose su original capacidad crítica.

La segunda consecuencia de la teoría, es decir, en lo que aquí nos interesa, la exclusión por vía de la consulta o previamente en sede legislativa de delitos de peligro abstracto sumó variadas críticas, en parte debidas a la debilitación del mismo concepto de bien jurídico. Es así como se entiende que un límite de tal naturaleza, además de atentar contra la facultad del legislador de configurar los delitos anticipando el umbral de tutela, desconoce las diversas formas que un bien jurídico puede asumir, no siendo posible asignar ni rechazar ab initio formas de lesión o puestas en peligro $^{16}$. Buena parte del descrédito o debilitamiento de la teoría se debe, además, a la confusa evolución de la teoría del bien jurídico que conoce en la actualidad diversas clasificaciones, que van desde bienes jurídicos indeterminados hasta la tutela de funciones ${ }^{17}$ que, como puede entenderse, admiten diversos grados de ofensa, muchos de ellos reconducibles, precisamente, al peligro abstracto o presunto. Por otra parte, se agrega a este proceso de debilitamiento la presunta pérdida de centralidad del estatus de libertad del sujeto, es decir, la progresiva pérdida de centralidad de la pena privativa de libertad, pues el aparato punitivo hoy recurre a diversas

13 Fiandaca, Giovanni (2003). "Nessun reato senza offesa”. En Fiandaca, G. y De Chiara, G. Una introduzione al sistema penale. Napoli: Jovene, pp. 103-157, p. 119, dice que se trataría de una verdadera "jaula teológica" - de teología laica- que anularía la dialéctica democrática 119.

14 Parodi Giusino, Manfredi (1990). I Reati di pericolo tra dogmatica e politica criminale. Milano: Giuffrè, p. 144

15 Manes (2005) 71.

16 Fiandaca (2003) 143. En contra de esta postura, Fiore, Carlo (1994). "Il principio di offensività". L'Indice penale, fasc. 2, pp. 275-288, p. 279, para quien esta reacción de la doctrina en los años 80, representada en figuras autorizadas como Fiandaca o el mismo Mantovani, se debió, en parte, a lo que propugnaban los defensores del principio de constitucionalización de ofensividad, en el entendido que numerosísimos delitos de peligro "no concreto" arriesgaban la ilegitimidad; sin embargo, esto habría portado a una inaceptable situación donde el principio acepta "derogaciones" como los delitos sin ofensa. Para esta evolución, Manes (2005) 79 y ss. 
respuestas sancionatorias, situación que termina por incidir en la base de la teoría de Bricola, quien convierte la libertad personal (ya no más o menos amenazada por la sanción penal) en clave del sistema de constitucionalización del bien jurídico con las consecuencias limitantes que la teórica preveía $^{18}$. Es decir, si la libertad personal ya no se encuentra tan amenazada por una pena privativa de libertad -piénsese, por ejemplo, que muchos delitos de peligro presunto pertenecen al área de los delitos del derecho penal económico que consultan penas de cárcel relativamente bajas y que aceptan la posibilidad de remisiones o cumplimientos en libertad-, sería válido para la política criminal recurrir a ellos al no afectar precisamente la base de la prohibición derivada de la ofensividad. A ello se suman críticas dirigidas a que se trata, sobre todo, de una tesis "académica" que mal se concilia con la idea de ofensividad que tiene la comunidad y, sobre todo, el legislador ${ }^{19}$, así como la observación que, a diferencia de los principios de legalidad o culpabilidad, la ofensividad carece de un contenido real y predeterminado siempre ${ }^{20}$.

En este horizonte, la teoría de la constitucionalización del principio de ofensividad fuerte ha dejado al paso a declinaciones menos cerradas teóricamente y más abiertas a posibles excepciones ${ }^{21}$-la denominada "ofensividad débil- así como su inclusión en otros principios, destacándose los de racionalidad y proporcionalidad ${ }^{22}$, lo cual, como ve-

18 Este argumento es rebatido. Así Manes (2005) 130 y ss. aclara que si bien es cierto que la pena privativa ha perdido buena parte de su incidencia efectiva, ello no elimina consecuencias gravosas para la libertad personal del individuo en fase de investigación y juicio, así como los efectos estigmatizantes de una posible condena. Estos gravosos efectos, aun sin condena, inciden "sobre el estatus de un determinado sujeto y en el conjunto de relaciones en el cual el mismo se encuadra, prescindiendo del sacrificio de la libertad personal amenazada o perpetrada, o de la efectividad de la pena personal (o de todos modos, de las penas accesorias), o, todavía, en ocasiones, prescindiendo de la verificación de responsabilidad a cargo del imputado" (p. 150). Véase también en este sentido Orlandi, Renzo (1997). "Effettività della sanzione penale e pricipi processuali". En Critica del Diritto, fasc. 4, pp. 212-228, p. 217 ss.

19 FiAndaca (2003) 125.

20 Palazzo, Francesco (1998). "Offensività e ragionevolezza nel controllo di costituzionalità sul contenuto delle leggi penali”. Rivista italiana di diritto e procedura penale, fasc. 2, pp. 350-384.

21 Para Mantovani, Ferrando (2009), Diritto penale, parte generale. Padova: Cedam, p. 198, se trata de un principio regulador que puede sufrir derogaciones cuando se trata de la prevención de bienes primarios, reclamando a su turno el criterio de la "racionalidad". Para Padovani, Tulio (2008), Diritto penale, novena edición, Milano: Giuffrè, p. 82, junto a los delitos de ofensa (al bien jurídico) se alinean aquellos de finalidad (scopo) como la tipificación del porte de armas o del juego de azar, al no tutelar ningún bien jurídico. En tanto, Donini, (1996) 18-25, se refiere a la paradoja de un texto constitucional que no ha mutado en el tiempo pero al cual, desde el punto de vista penal, se le han atribuido claves de lectura dogmática absolutamente diversas en una distancia temporal de poco más de 30 años.

22 Fiandaca (2003) 143, para quien el principio no puede radicalizarse, sino funcionar en una lógica gradualística, balanceando el contenido del principio con las exigencias políticocriminales que coliden con el. 
remos en el próximo apartado, ha sido, en parte, el camino que la Corte Constitucional ha asumido. Es decir, una perspectiva $f l o u^{23}$, abierta a posibles renuncias frente a otros principios o estrategias de tutela de bienes jurídicos ${ }^{24}$.

\subsection{2) La ofensividad en el Código Penal de 1930}

Fuera de la Constitución, la doctrina ha buscado identificar el principio de ofensividad en el Código Penal, particularmente en las disposiciones que tratan de la tentativa. La tentativa se encuentra regulada en el art. $56^{25}$ al cual, con el objeto de tener una visión completa sobre el punto, debe agregarse la regulación del delito imposible del art. 49 inciso $2^{\circ 26}$. Es fácil advertir el porqué de este reclamo a las normas del delito no consumado: mientras otros códigos de su época raramente se refieren al delito imposible o, más en general, a la tentativa inidónea, el Código del 30 parece tomar una postura clara sobre el particular, lo que permitiría, según sus defensores, establecer un principio general de ofensividad como eje para la interpretación de los tipos penales y que irrogaría sus efectos a otras categorías de delito, entre ellos, los delitos de peligro ${ }^{27}$, puesto que, de una parte, la tentativa se castiga en caso de actos idóneos, dirigidos de modo inequívoco a la comisión de un delito, descartándose la punibilidad de tentativas meramente inidóneas.

Esta postura ha sido fuertemente criticada, en el entendido que, ya sea por la ratio, ya sea por su estructura, la tentativa no puede asimilarse a los delitos de peligro en general, siendo mayoritaria la postura que entiende que el art. 49 inciso $2^{\circ}$ es solo un "doble" de la misma norma del art. 56 y que, por ello, no dice nada acerca de un principio de orden general $^{28}$. Sobre todo, se critica la asimilación del concepto de idoneidad,

23 Manes (2005) 74 y ss.

24 Recientemente cobran vigor las posturas que se basan en criterios de necesidad y merecimiento de pena. Ver, por todos, Fiandaca (2003) 124.

25 Art. 56, inciso 1. Tentativa: Quien ejecuta actos idóneos, orientados en modo inequívoco a cometer un delito, responde de delito tentado, si la acción no se ejecuta o el resultado no se verifica.

26 Art. 49, inciso 2: Delito erróneamente supuesto y delito imposible: La punibilidad es del mismo modo excluida cuando, por la inidoneidad de la acción o por la inexistencia del objeto, resulta imposible el resultado dańoso o peligroso

27 Con particular insistencia, Gallo, Ettore (1987), Voz "Attentato (delitto di)". Novissimo Digesto italiano, Apendice, IV edizione, (pp. 561-576), Torino: Utet, p. 565. De hecho, el autor entiende que es esta norma la que fundamenta el principio de ofensividad o también conocido como "principio realístico", rechazando en cambio que la Constitución italiana funde dicho principio del art. 25, tendencia por lo demás generalizada en varios autores. Véase también Grasso (1986) 693, Parodi Giusino (1990) 403, Mantovani (2009) 202.

28 Véase, por todos, Romano, Mario (2004), Comentario sistematico del Codice penale, Terza edizione. Milano: Giuffré, vol., 1 p. 512 y sgtes.; Donini (1996) 173, quien entiende que la base del juicio (prognosis póstuma) en los delitos tentados se integre con conocimientos on- 
al cual se refiere el art. 56 que no coincide con el nivel de probabilidad que se exige en los delitos de peligro en general, y tampoco con el de peligro abstracto en particular, dado que un acto idóneo es uno en el cual el grado de posibilidad se satisface siempre que no sea igual a cero, es decir, en el cual la posibilidad no se encuentre absolutamente excluida, mientras en los delitos de peligro, sean estos concretos o abstractos, esa posibilidad debe reunir características de mayor certeza, diferenciándose, claro está, como examinaremos más adelante, entre las dos clásicas especies de peligro $^{29}$. Por ello, también tiende a rechazarse la idea que las normas de la tentativa consagren un principio de carácter general de ofensividad.

\section{2) EL PRINCIPIO DE OFENSIVIDAD EN CHILE}

\subsection{1) La teoría del bien jurídico en la dogmática chilena}

En nuestra doctrina, como en la italiana, es relativamente pacífico que el derecho penal tiene como (una) misión la protección de intereses meritorios de tutela con la sanción máxima ${ }^{30}$. Sin embargo, como es obvio, no presenta las mismas características, en principio, que la teoría constitucionalizada del bien jurídico o del principio de ofensividad.

La mayor parte de la doctrina chilena está de acuerdo en que la Constitución no ha consagrado el principio del bien jurídico, exclusiva protección de bienes jurídicos o de merecimiento de pena, en forma expresa $^{31}$, aunque todos pretenden deducirlo de otras disposiciones de la misma Carta, particularmente del principio de legalidad, contenido en el mismo artículo y número, en sus incisos $7^{\circ}$ y $8^{\circ}$, pues "el tipo legal solo

tológicos propios de un sujeto ideal constituido por el mejor modelo de agente experto según los distintos sectores de referencia y el conocimiento nomológico de la mejor ciencia y experiencia, sin considerar, en cambio, el conocimiento relativo a situaciones objetivamente existentes al momento de la conducta pero verificables solo a posteriori que, a la inversa, sí integrarían los delitos denominados "de evento de peligro". Véase también Pagliaro, Antonio (2007), "Il reato". En Grosso, C.F., Padovani, T., Pagliaro, A., Trattato di Diritto penale, Milano, Giuffrè, p. 27.

29 Véase especialmente Angioni, Francesco (1984), Il pericolo come elemento della fattispecie penale: la struttura oggettiva. Segunda edición, Milano: Giuffré, p. 259, el cual explica que es idónea toda acción que haga posible la verificación del resultado y, entonces, también los actos no peligrosos, pero idóneos si están orientados en forma inequívoca a la producción del resultado son punibles a título de tentativo.

30 Véase Ossandón Widow, María (2009), La Formulación de tipos penales. Valoración critica de los instrumentos de técnica legislativa, Santiago: Jurídica de Chile, p. 23; Rettig EspinoZA, Mauricio (2009), "Desarrollo previsible de la relación entre la antijuridicidad y la culpabilidad”, en Revista de Derecho (Valdivia), vol. XXII, N² 2, pp. 185-203, p. 187.

31 Cfr. Matus Acuña, Jean Pierre (1996), "Sobre la necesidad constitucional de la existencia de un bien jurídico a proteger por los tipos penales". En Revista Universum, Talca, $\mathrm{n}^{\circ} 11$, pp. 123 a 132; Mera, Jorge (1998), Derechos humanos en el Derecho penal chileno. Santiago: ConoSur, p. 148; Cury Urzúa, Enrique (2005) Derecho penal parte general. Santiago: Ediciones Universidad Católica de Chile, p. 55. 
puede determinarse realmente, esto es, conocerse su contenido preciso y alcance efectivo, sus límites, a partir del bien jurídico protegido" 32 o al de proporcionalidad en sentido estricto ${ }^{33}$ o porque la Constitución consagra un determinado modelo de descriminalización, basado en el respeto del contenido mínimo de los derechos consagrado en el artículo 19 n $^{\circ} 26$ de la Carta Fundamental, o porque se extrae de los conceptos que la Constitución emplea, tales como República democrática y de la limitación a la soberanía basada en el respeto de los derechos fundamentales, que permitiría reconstruir el concepto de bien jurídico desde la Constitución, del mismo modo que se ha hecho en Alemania, Espańa o Italia, descartando así la posibilidad de "atribuir el carácter de bienes jurídicos a prescripciones morales o ideológicas, lesionando las libertades básicas de los ciudadanos amparadas por la Carta Fundamental" 34 .

Respecto a las funciones que asume el bien jurídico, se reconocen al menos dos que se asemejan a las funciones que han desarrollado también en otras latitudes: una política o de garantía, en todo caso de lege ferenda, y otra hermeneútica, teleológica, sistemática o exegética del bien jurídico, esta vez, de lege lata. Respecto de la primera, se reconoce que, tras ella, "yacen, en verdad, viejos problemas escolares, esto es, de iusfilosofía punitiva" 35 y de dificultades no menores, pues aparecen a la hora de precisar cuáles son los criterios que deben dar base al concepto material de bien jurídico ${ }^{36}$, pues se conecta con cuestiones tales como la justificación del ius puniendi. Esta función es reconocida en la manualística y obras especializadas ${ }^{37}$. Otros autores señalan que dado que en la sociedad con-

32 Mera (1998), 148. Sin referirse directamente a la Constitución chilena, Durán Migliardi Mario (2011), "Constitución y legitimación de la pena. Apuntes teleológicos sobre el rol de la Constitución en el sistema penal”. En Política criminal, n 11 , junio 2011, pp. 142-162, p. 152, entiende que la Constitución funciona también, de modo similar, a lo señalado por la doctrina italiana, como "catálogo" de bienes.

33 Cfr. Ossandón Widow (2009), 461 y sgtes. La autora, quien se refiere en esta sección especialmente al Derecho español, aclara en página 464 que este principio no se encuentra consagrado expresamente en la Constitución de ese país, pero que puede reconstruirse a partir del concepto de Estado de Derecho y de la esencia misma de los derechos fundamentales. No lo dice expresamente, pero creo entender que dicho razonamiento puede ser extensible a nuestro sistema jurídico.

34 Cury, ob. cit., p. 55. En todo caso el autor, al considerar la noción de bien jurídico como preexistente a su consagración como tal en el Derecho, no considera necesaria su incardinación constitucional. Cfr. ídem, p. 55. En el mismo sentido, Politoff, Matus y Ramírez (2006), Lecciones de Derecho penal chileno. Parte general. Santiago: Editorial Jurídica de Chile, p. 69.

35 Guzmán Dalbora, José Luis (2001). El delito de amenazas, Santiago: LexisNexis, p. 18.

36 Carnevali Rodríguez, Raúl (2000) "Algunas reflexiones en relación a la protección penal de los bienes jurídicos supraindividuales". En Revista Chilena de Derecho, vol. $\mathrm{n}^{\circ} 27, \mathrm{n}^{\circ}$ 1, pp. 135 a 153, p. 137. Un esbozo de esta función puede verse en Del Río, Raimundo (1945), Explicaciones de Derecho penal, dos tomos, Santiago: Nascimento, tomo I, p. 208.

37 Así, en la manualística, Politoff, Matus y Ramírez, quienes, basados en Hassemer, sostienen que esta función implica "la posibilidad de decidir cuándo, con respecto a determinados 
temporánea la soberanía procede del pueblo, solo se justifica la protección penal de bienes que pertenecen a todos los integrantes de la comunidad ${ }^{38}$, como una forma de rechazar la incriminación de conductas que no lesionen o pongan en peligro un bien específico, sino sentimientos éticos o morales ${ }^{39}$; se habla también de "principio de exclusiva protección de bienes jurídicos" 40 . En lo que respecta a su ubicación sistemática o pertenencia, las opiniones son discrepantes: para algunos, aparentemente se trata de un principio independiente, incardinado directamente en los límites del ius puniendi $i^{41}$, otros consideran que deriva o pertenece a otros principios, como el de "prohibición de exceso o principio de proporcionalidad en sentido amplio" 42 .

La segunda función tradicionalmente asignada al concepto de bien jurídico es una función metodológica, de interpretación, teleológica e incluso exegética, es decir, que el bien jurídico sea una noción que permita dar con el sentido objetivo de una incriminación determinada. Buena parte de la doctrina nacional reconoce esta función ${ }^{43}$, siendo también

bienes jurídicos, el derecho penal constituye un instrumento necesario y apropiado. (...) Tal noción importa, además, como dirección de política criminal (...), impugnar toda pretensión del legislador de limitar la libertad individual, mediante incriminaciones, cuando no se trate de afirmar la enérgica tutela de un bien jurídico". Politoff, Sergio; Matus, Jean Pierre y Ramírez, María Cecilia (2004), Lecciones de derecho penal chileno. Parte general. Santiago: Jurídica de Chile, p. 68. En obras especializadas, véase Ossandón Widow (2009), 469, y Vargas Pinto, Tatiana (2007), Delitos de peligro abstracto y resultado. Determinación de la incertidumbre penalmente relevante. Pamplona: Thomson Aranzadi, passim, especialmente p. 68; Rettig Espinoza (2009) 187.

38 Cury Urzúa (2005) 53.

39 Bustos Ramírez, Juan y Hormazábal Malarée, Hernán (1997). Lecciones de Derecho penal, Madrid: Trotta, tomo I, p. 61, y Náquira Riveros, Jaime (1998). Derecho penal. Teoría del delito. Santiago: McGraw-Hill, tomo I, p. 74.

40 Carnevali Rodríguez, Raúl, (2008). "Derecho penal como ultima ratio. Hacia una política criminal racional”. En Ius et Praxis, n 1, año 14, pp. 13 a 48, p. 43. Expresa con particular intensidad la importancia de este principio Rivacoвa y Rivacoba, Manuel (1999). "Introducción al estudio de los principios cardinales del Derecho penal". En Direito e Ciudadania, ano II, n 6, pp. 57-72, p. 67: "Por donde se ve que el Derecho penal (...) no puede obrar, ni siquiera cabe imaginarlo sin que medie significativa afectación de algún bien de esta índole, o sea, de un bien jurídico de notable entidad, y se hace patente el principio de ofensividad".

41 Cfr. Carnevali Rodríguez (2008) 43. Así también parece entenderlo Fernández Cruz, José Ángel (2010). "El juicio constitucional de proporcionalidad de las leyes penales ¿La legitimación democrática como medio para mitigar su inherente irracionalidad?”. En Revista de Derecho U. Católica del Norte, $\mathrm{n}^{\circ}$ 1, pp. 51-99, p. 74. Específicamente este autor lo reconoce como un presupuesto del juicio de proporcionalidad.

42 Oliver Calderón, Guillermo (2007). Retroactividad e irretroactividad de las leyes penales. Santiago: Editorial Jurídica de Chile, p. 294 y siguientes. El autor, luego de pasar revista por sus denominaciones y consagración constitucional, se detiene en el análisis de su contenido, desmembrado en los subprincipios de idoneidad o adecuación al fin, necesidad, dividido a su vez en exclusiva protección de bienes jurídicos, subsidiriedad y fragmentariedad y, por último, Proporcionalidad en sentido estricto.

43 Politoff, Matus y Ramírez (2004) 69. 
posible encontrar autores que plantean que el bien jurídico tiene una función "exegética" y "sistemática", es decir, que el bien jurídico es, sin duda, un criterio teleológico guía en la interpretación de la ley, y que, en consecuencia, "[e]l bien jurídico es un núcleo central vivo del tipo penal en torno al cual giran, se sustentan y se explican todos los elementos objetivos y subjetivos" y que además "es un criterio jurídicopenal adecuado para clasificar las diversas figuras delictivas contenidas en la parte especial de la legislación penal, considerando la gravedad del ataque" ${ }^{44}$. Otros autores lo entienden en términos más acotados, como elemento constitutivo de la antijuridicidad: "[P] ara establecer, en consecuencia, si una conducta típica es contraria al Derecho, es decir, si es sustancialmente injusta, es preciso empinarse por sobre la mera descripción formal, carente de contenido valorativo, que aparece en el tipo y juzgarla impersonalmente en relación con todo el ordenamiento jurídico. Comprobado que esa conducta no guarda la debida conformidad con las exigencias del Derecho, lo que concretamente sucede cada vez que lesiona o pone en peligro un bien jurídico determinado, hemos de tenerla por injusta o antijurídica" 45.

Más recientemente se ha venido desarrollando una posición que, desde diversos ángulos, discute la prevalencia del principio de lesividad o necesaria lesión (o puesta en peligro) de bienes jurídicos, pues el mismo no estaría exento de objeciones o, en todo caso, no tendría la fuerza para impedir la punibilidad de delitos de peligro abstracto ${ }^{46}$. Otro autor, expresamente rechaza que sea función del derecho penal la protección de bienes jurídicos, concibiéndolo solo como otro principio que legitima el ordenamiento punitivo ${ }^{47}$ junto a otras estructuras. También, desde otra perspectiva, se ha defendido la necesaria ofensividad, al concebir la inexistencia de delitos "sin resultado" 48 .

A modo de conclusión de este apartado, creo que puede afirmarse que en Chile tiende a prevalecer, con todo, una posición más clásica respecto al contenido de la antijuridicidad, esto es, como aquella que la

$44 \quad$ Náquira (1998) 74. En términos similares GuZMán Dalbora (2001) 15.

45 Novoa Monreal, Eduardo (2005). Curso de Derecho penal chileno. Parte general, Santiago: Editorial Jurídica de Chile, tomo I, p. 313.

46 Mañalich, Juan Pablo (2004). "La tentativa y el desestimiento en el derecho penal. Algunas consideraciones conceptuales”. En Revista de estudios de la Justicia, n 4, pp. 137-175, p. 152

47 Así, expresamente PiÑa Rochefort, Juan Ignacio (2010). Derecho penal, fundamentos de la responsabilidad. Santiago: AbeledoPerrot, p. 250, para quien la función del derecho penal es "la protección de un orden valioso, de un sistema de expectativas que permite a los ciudadanos desenvolverse con relativa normalidad. La función de los bienes jurídicos es mantener orientada la operación del sistema penal al cumplimiento de esa función, pero no es su cumplimiento mismo".

48 Así Vargas Pinto, quien en primer lugar defiende, precisamente, la noción que nos parece correcta, ofensividad (alternativamente: afectación, ofensa, perturbación o agresión, p. 197). Si bien no ocupa el término "principio de ofensividad", su defensa se desprendería de su concepción de delitos con resultado siempre necesario. Vargas Pinto (2007) 207. 
concibe como efectiva lesión o puesta en peligro de bienes jurídicos. No hay, en cambio, acuerdo respecto a la autonomía del principio ni a su consagración constitucional, o al menos, no hay acuerdo respecto a la intensidad de sus efectos en sede legislativa ni judicial.

\section{3) LA OFENSIVIDAD EN LA JURISPRUDENCIA CONSTITUCIONAL}

\section{1) LOS DELITOS DE PELIGRO ABSTRACTO COMO BANCO DE PRUEBA}

\subsection{1) El peligro abstracto en el sistema italiano}

A juicio de quien escribe, los delitos de peligro abstracto se prestan como un excelente conejillo de Indias para medir la fuerza o el impacto de cualquier teoría que tome en consideración el bien jurídico y, por ende, la lesividad $\mathrm{u}$ ofensividad como principio del derecho penal (por supuesto, sin prejuzgar ni el contenido asignado al principio ni sus resultados). Ello se debe a que no hay otra parte de la teoría del delito más atormentada que esta, pues los delitos de peligro abstracto, al menos tradicionalmente entendidos, caen bajo la sospecha de un escaso indice de lesividad, de ser presunciones de responsabilidad o, peor aún, delitos de mera desobediencia. $\mathrm{Y}$, al mismo tiempo, parecen ser un recurso irrenunciable del legislador contemporáneo, que se vería obligado a utilizarlo en presencia de ciertos supuestos, como cuando el objeto de la tutela son bienes jurídicos supraindividuales que solo pueden ser ofendidos (lesionados) por conductas acumulativas, o en donde los mismos conceptos de lesión y puesta en peligro resultan difíciles de determinar con precisión o, en general, si se trata de conductas que se inscriben en el fenómeno de la sociedad del riesgo, como adecuado equilibrio entre las exigencias de seguridad de la comunidad y el desarrollo tecnológico.

Abordar la extensa literatura sobre el tema en Italia es una empresa que excede los objetivos de este trabajo. Trataremos de hacer un brevísimo resumen. La doctrina de la península se ha movido, al igual que en otros ordenamientos, bajo la premisa de una distinción fundamental: el peligro concreto y el peligro abstracto. La distinción clásica reza que en los primeros el peligro es parte del tipo y, por ende, debe verificarse (concretamente) y ser, a su turno, acreditado en juicio; mientras en los segundos, el peligro sería solo la ratio del legislador quien entiende que ciertas conductas son peligrosas en todo caso (en base a criterios estadísticos) y no se requiere de su verificación factual ${ }^{49}$.

49 La literatura acerca de estos delitos es inabarcable para un trabajo como este. Nos remitimos a la manualística, donde la precitada distinción se encuentra con matices. Así, en lo que se 
A esta clásica distinción una parte de la teoría italiana agrega más recientemente una tercera categoría, más allá de esta pareja conceptual, el peligro presunto. Este sería aquel en donde la peligrosidad de la conducta ni siquiera podría verificarse in abstracto y, por tanto, se trata de una presunción (más bien una ficción ${ }^{50}$ ) y terminan por representar delitos de mera desobediencia ${ }^{51}$ y, por ende, ajenos a la verdadera estructura de los

refiere a delitos de peligro concreto, PARodi Giusino (1990) 279, para quien la diferencia entre peligro abstracto y concreto se resuelve en un problema de técnica legislativa. Fiandaca y Musco (2001) 179; Marinucci, Giorgio y Dolcini, Emilio (2009). Manuale di diritto penale. Parte Generale. Terza edizione. Milano: Giuffrè, p. 171; Pagliaro (2007) 33; Padovani (2008) 135; Palazzo, Francesco (2008). Corso di Diritto penale, parte generale. Terza edizione. Torino: Giappichelli, p. 76. Mantovani (2009) 220, quien, respecto de los delitos de peligro abstracto, agrega que "se trata de tipos de delito que precluyen la posibilidad ex ante y, a veces, también ex post de controlar la existencia o no de las condiciones para la verificación del resultado lesivo". Esta postura de la falta de control del resultado acerca esta postura a la asumida en Chile por Vargas Pinto, T., (2007), Delitos de peligro abstracto y resultado, Pamplona: Aranzadi, p. 438, refiriéndose a los por ella denominados "delitos de puesta en peligro abstracto"; para un examen específico y bien documentado, se recomiendan los artículos de Canestrari, Stefano (1991). "Reati di pericolo". En Enciclopedia Giuridica Treccani, t. XXVL, pp. 1-10, p. 2; Grasso (1986) 697; Angioni (1983) 109, indica, a su turno, que los conceptos descriptivos empleados por el legislador están "tan cargados de de sentido que es difícil imaginar un hecho típico que no sea, al mismo tiempo, peligroso concretamente o lesivo para el bien jurídico". También se acerca a la característica de la incontrolabilidad cuando indica, respecto a aquellos delitos donde el desvalor se funda en un resultado naturalístico que no verifica instantáneamente pero se produce y agota en un lapso amplio "ninguno se encuentra en posición de excluir, de partida, si habrán personas que serán lesionadas o concretamente puestas en peligro en su incolumidad (...). En esta hipótesis la vinculación con el bien jurídico no expreso consistiría propiamente no en un peligro concreto, sino en la no exclusión de un peligro concreto (p. 110). Véase también Moccia, Sergio (2003). El derecho penal entre ser y valor. Traducción de Antonio Bonnano. Montevideo: BdF, p. 195 y ss.

50 Para Parodi GiUsino (1990) 231, “mientras abstraer quiere decir juzgar un hecho por las propiedades generales que ello tiene en común con otros hechos similares, dejando de lado las características individuales del caso concreto, a la inversa, presumir quiere decir (sobre todo si la presunción es absoluta) equiparar hechos, distintos entre sí, con el fin de aplicarles la misma disciplina jurídica”. Véase también Mantovani (2009) 221. Menos claro sobre la factibilidad de esta distinción CANESTRARI (1991) 8, quien parece reconocer su existencia pero utiliza ambos términos (abstracto y presunto) como sinónimos. Véase la interesante distinción de Gargani, Alberto (2005). Il danno qualificato dal pericolo. Torino, Giappichelli, pp. 191-193 donde, a propósito de los delitos de peligró común distingue el pericolo concreto, definido como aquel en el cual "el juicio de peligro se refiere directamente al resultado temido (probabilidad de resultado de dańo)”, mientras el peligro abstracto es aquel en que "el juicio de peligro se substancia en la conducta, en cuyas modalidades está ínsito un peligro $<<$ che para actualizarse, implica un paso posterior $>>$ ” y es por naturaleza, un juicio "parcial y generalizante" en donde funciona "como adecuación lesiva que debe determinarse mediante parámetros generales, descuidando algunas circunstancias del hecho histórico”. Finalmente el peligro presunto sería "la técnica legislativa basada sobre la tipificación de formas de comportamiento regular y generalmente peligrosas. Se trata de un juicio deductivo que no tiene en cuenta el caso concreto, es decir, una fictio que precluye el control de las características del hecho concreto".

51 Véase Angioni (1983) 109, quien afirma que el peligro presunto es aquel "donde en ciertos casos concretos, aun correctamente subsumibles en el tipo abstracto el observador modelo que funge de sujeto del juicio de peligro excluye absolutamente la subsistencia de cualquier 
delitos de peligro. Quienes afirman esta clasificación consideran que la legitimidad constitucional, basada sobre todo en el principio de ofensividad, acepta la existencia de delitos de peligro concreto y abstracto, mas no de aquellos presuntos ${ }^{52}$. Sin embargo, esta posición, que diferencia dentro de los delitos de peligro abstracto aquellos propiamente abstractos de aquellos "presuntos", no es aceptada generalmente en doctrina, la cual tiende a utilizar ambos términos como sinónimos. A ello se agrega la dificultad de encontrar una diferencia clara entre ambas figuras ${ }^{53}$.

La evolución de la doctrina italiana sobre el particular es similar a la de otros ordenamientos, en el sentido de un inicial rechazo de esta figura bajo la premisa de un derecho penal de extrema o última ratio anclada a la idea de la lesión como presupuesto básico de la pena ${ }^{54}$. Esta evolución -repetimos, similar a la de otros sistemas jurídicos de matriz continental-

relación de peligro entre [el] hecho típico y la [lesión del] bien jurídico (...). Aquí el hecho punible no sería un hecho de una forma o de otra, ofensivo, sino una mera desobediencia y el desvalor correspondiente sería solo un desvalor interno".

52 Parodi Giusino (1990) 387: "De hecho, si hay una cosa que el legislador absolutamente no debe ni puede hacer, por cuanta libertad se le quiera entregar, es afirmar la existencia de un nexo causal ahí donde no existe (...). Una cosa es presumir que un hecho sea contrario al bien jurídico, otra cosa es presumir que ello pueda producir un cierto resultado. El primero es un juicio político, de valor, de oportunidad que solo el legislador puede realizar, sin que el juez lo sustituya; el segundo es un juicio de tipo causal (pronóstico) que solo el juez -sobre todo en materia penal- puede realizar, sin que el legislador lo sustituya". En términos similares, Fiore (1994) p. 281: la calificación del peligro como 'abstracto' (adjetivo que característicamente se contrapone a 'concreto' podría ser convencionalmente reservada a las hipótesis en las cuales, aun siendo evidente (respecto al esquema del peligro concreto) una anticipación de la tutela, la misma norma autoriza o, más aún, impone la valoración judicial, caso por caso, de la 'peligrosidad' de la conducta'; véase también Moccia (2003) 196, quien agrega un argumento de efectividad del sistema, afectado por la presencia de delitos de peligro abstracto: "Por otra parte, la dificultad de interiorizar la norma relativa a una figura jurídica de peligro abstracto va acompañada del elevado riesgo de una pérdida de credibilidad en el sistema que, al tener que intervenir con la sanción penal por hechos de leve entidad, desvaloriza sus armas. Tal característica debería distinguir a las figuras jurídicas de peligro abstracto, dado su disvalor de evento casi nulo, a menos que se desee incurrir en formas ulteriores de ilegitimidad, derivadas como mínimo de la violación de los principios de razonabilidad y de personalidad de la responsabilidad penal, cuando se vinculan con tales figuras sanciones particularmente duras".

53 Crítico de esta distinción Catenacci, Mauro (2006). "I reati di pericolo presunto fra diritto e processo penale”. En Dolcini, E. y Paliero, C.E. (ed.), Studi in onore di Giorgio Marinucci, Milano: Giuffrè, pp. 1415-1442, p. 1419, el cual entiende que este intento, por lo demás, busca "minimizar" el problema, aludiendo que los delitos de peligro presunto -inconstitucionales- serían una cantidad muy menor. De hecho, cuando se buscan ejemplos se suele recurrir casi unívocamente a la figura del art. 445, el cual reza "quien, ejercitando, aun abusivamente, el comercio de sustancias medicinales, las suministra en especie, calidad o cantidad que no correspondan a la prescripción médica, o diferente de la declarada o acordada, es castigado con la reclusión de seis meses a dos años y con la multa de €103 a €1.032". En efecto, en este caso la barrera de punición se adelanta en exceso, pues no está dicho que una suministración de medicinas distinta de aquella que aparece en la "receta" sea de por sí peligrosa para la salud, bien jurídico tutelado por la norma.

54 Expone en sus líneas más generales esta línea evolutiva Donini (2004) p. 100 y ss. 
se enriquece, luego, con la teoría de la constitucionalización del principio de ofensividad, como hemos visto en el apartado anterior. Esta línea evolutiva comienza a cambiar a inicios de la década del 80 hasta el día de hoy, momento en el cual se puede decir, sin temor a equivocarnos, que la doctrina italiana, dentro de ciertos límites, acepta la existencia de figuras de peligro abstracto o presunto sin las viejas reticencias de antaño ${ }^{55}$. Las razones para ello -dando por descontado que aquellos de peligro concreto presentan menos dificultades en el proceso de adecuación a los principios constitucionales aunque son también objeto de críticas- radica en dos datos: que, dentro de los límites de ciertos principios como el de racionalidad, el legislador es libre para determinar, en el tipo, los presupuestos de la punibilidad, aun si ellos versan en una presunción ${ }^{56}$. A este fundamento -a decir verdad bastante anclado en la vieja concepción autoritaria del legislador del 30- se agrega que un ordenamiento jurídico orientado a la tutela de bienes jurídicos (sobre todo, aunque no únicamente supraindividuales) no puede renunciar a una técnica de tutela como el peligro abstracto, al menos en ciertos ámbitos de la vida, afectados de un índice altísimo de riesgo debido a la modernidad ${ }^{57}$ y que, de todos modos, en el peligro abstractamente considerado, las razones para tipificar dichas conductas existen en la realidad estadística por lo que el legislador no estaría andando más allá de aquello permitido en la Carta Fundamental.

Por cierto, se reconocen también las dificultades para conciliar estos delitos con el principio de ofensividad ${ }^{58}$, el cual, en principio, excluiría la posibilidad de la existencia de delitos sin puesta en peligro (concreta) del bien jurídico. Es decir, lo que sucedería en el clásico supuesto de una conducta que abstractamente reuniese los requisitos del tipo pero, concretamente, no hubiese acarreado ningún peligro para el bien. En estos casos, la doctrina ha construido una serie de limitaciones que pueden resumirse como sigue: el peligro abstracto solo debe ser utilizado por el legislador para la protección de bienes jurídicos de particular relevancia, anticipando así la tutela justificadamente ${ }^{59,60}$, siempre que las consecuencias san-

55 Según Donini (2004) 103, esta modificación responde a lo que denomina "Derecho penal moderno", es decir, aquel nacido luego de la Segunda Guerra Mundial.

56 Véase Pagliaro (2007) 33: "mientras es verdad que no puede haber delito donde no haya sido ofendido (lesionado o puesto en peligro) el bien protegido por la ley, es cierto también que la verificación de esta ofensa se debe juzgar desde el punto de vista del legislador".

57 Véase, Padovani (2008) 136; Grasso (1986) 718; Mantovani (2009) 217; Valenti (2006) 290; Pulitanò (1976) 171; Donini (2004) 104; Salcuni (2007) 2906.

58 Fiandaca (1984) 453; Donini (1996) 191; Padovani (2008) 136; Parodi Giusino (1990) 382.

59 Véase, por todos, Padovani (2008) 136.

60 Se debe, en todo caso, advertir que la relación entre la técnica de la tutela y el bien tutelado es de particular relevancia en este aspecto, relevancia que no siempre ha sido acogida con suficiente consciencia ni por la doctrina ni por la casación (menos aún por el legislador). En otras palabras, será el tipo de bien jurídico que se desea proteger el que determina el tipo de 
cionatorias sean mucho más benévolas que un delito de lesión o peligro concreto $^{61}$, una progresiva disminución de estos o su modificación en contravenciones $^{62}$ y que, en sede de técnica legislativa, el peligro ínsito en la conducta tipificada sea de tal modo evidente que la exclusión del riesgo en el caso concreto sea marginal o muy difícil ${ }^{63}$.

A esta situación doctrinal podría dársele el calificativo de pax; en efecto, la ciencia penal italiana parece compartir ampliamente las conclusiones a las que hemos arribado más arriba, pero ello no significa que no existan voces disidentes. Así, recientemente, un autor objeta ese aparente acuerdo, sobre todo de cara a cómo la jurisprudencia italiana entiende estos delitos, de una forma, al menos, "errática”, lo que es efecto de la ausencia en la literatura de indicaciones unívocas acerca de los remedios concretos para evitar la punición de comportamientos aparentemente típicos pero, en realidad, inofensivos ${ }^{64}$, así como la poco convincente diferenciación entre delitos de peligro abstracto y presunto, como hemos visto, enunciada por una parte de la doctrina ${ }^{65}$; objetando, además, que, como quiere una parte de la ciencia penal italiana, que el problema de los delitos de peligro abstracto o presunto se reduzca a una cantidad muy menor de ilícitos, puesto que la cantidad no dice nada acerca de la urgencia de encontrar remedios adecuados para su interpretación ${ }^{66}$. Así, basándose en una tendencia uniforme de la Corte Constitucional, la cual reconoce el principio de ofensividad -pero, como veremos más adelante, en términos de racionalidad y proporcionalidad-, el autor indica como vía de escape para el caso de situaciones formalmente típicas pero no ofensivas del bien jurídico, el decidido cambio de la presunción jures et de jure, parte integrante de la estructura tradicional de los delitos de peligro, a una presunción jures tantum que permita, en consecuencia, la prueba de la no ofensividad del hecho concreto ${ }^{67}$. Esta última postura, que presenta el flanco a críticas derivadas de una posible inversión del onus probandi,

protección que la ley penal debe reservarle y no a la inversa (Véase Angioni (1983) 7). Para ello, una adecuada clasificación de los bienes jurídicos y una muy urgente revisión de sus límites son imprescindibles, pues existen objetos más proclives a la protección por medio de la técnica del peligro y otros más proclives a la técnica de la lesión. Así, aún se discute la existencia de bienes primarios, finales, instrumentales, bienes-función, etc.

61 Donini (1996) 172; Parodi Giusino (1990) 435.

62 Pelissero, Marco (2008). Pericolosità sociale e doppio binario. Torino: Giappichelli, p. 468; DONINi (1996) 194.

63 Fiandaca (1984) 464; esta idea lleva a autores como Marinucci y Dolcini (2009) 172, a entender que los delitos de peligro abstracto o presunto son una gama muy restringida de ilícitos, en la cual, a fin de cuentas, los otros mecanismos de tutela han demostrado ser ineficaces.

64 Catenacci (2006) 1417-1418.

65 Catenacci (2006) 1419.

66 Catenacci (2006) 1420

67 Catenacci (2006) 1434-1438. Esta posición ya era compartida, en términos similares por Fiore (1994) 282, Pagliaro (2007) 33 y Mantovani (2009) 221. 
refleja las dificultades casi insalvables que muestra esta categoría al enfrentarla a principios como la ofensividad. De todos modos esta postura está aún lejos de ser admitida doctrinalmente.

\subsection{2) El peligro abstracto en el sistema chileno}

En Chile, la literatura no es tan extensa como la italiana, pero no deja de ser igualmente intensa, compartiendo en parte los resultados de la evolución antedicha. En la doctrina tradicional chilena, los delitos de peligro abstracto constituyen, como en otros ordenamientos, una categoría que, al menos en apariencia, se basan en una presunción iuris et de iure, pues se presume que la conducta tipificada siempre constituye un peligro, aun cuando este no se verifique materialmente, verificación que sí se exige en los de peligro concreto ${ }^{68}$. A su vez, una parte importante de los autores considera que en estos delitos el peligro es solo el motivo del legislador para incriminar la conducta, no siendo parte integrante del tipo.

Respecto al criterio para determinar dicha presunción se suele acudir a los de probabilidad o posibilidad, en todo caso, estadística ${ }^{69}$ acerca de que ciertos actos, de acuerdo a la observación persistente de sus resultados, permiten concluir que estos, considerados en abstracto, tienden a producir resultados lesivos que el ordenamiento jurídico quiere proteger antes de su destrucción o menoscabo ${ }^{70}$. Un sector aún minoritario de la doctrina agrega que el motivo de la punición de estas conductas en que el peligro no es exigido, se debe a que, de no punirse, aumentarían en forma desmedida, afectando en forma grave e irreparable el bien jurídico que se pretende proteger. Es decir, solo el conjunto de las conductas punibles podrían poner "en peligro concreto" el bien tutelado, lo que no se logra con una única acción. Finalmente, si bien no puede afirmarse en todos los casos, se entiende que estos delitos protegen preferentemente bienes jurí-

68 Acerca de esta presunción, se pronuncian como característica de estos delitos CuRY URZÚA (2005) 292 (aunque con reservas, como veremos luego); Etcheberry, Alfredo (1997). Derecho penal. Tercera edición. Santiago: Jurídica de Chile, vol. I, p. 185; Maldonado, Francisco (2006) "Reflexiones sobre las técnicas de tipificación de los llamados delitos de peligro en el moderno Derecho penal”. En Revista de Estudios de la Justicia, 7, pp. 23-63, p. 30; Politoff, Matus y Ramírez (2004) 211; Garrido Montt, Mario (2003). Derecho penal. Tercera edición. Santiago: Jurídica de Chile, tomo II, p. 253; Bustos Ramírez y Hormazábal Malaree (1997), tomo II, 43.

69 Cury (2005) 293; Maldonado (2006) 31; Vargas Pinto (2007) 223, aunque con un contenido más preciso.

70 Se aparta de esta línea Mañalich, Juan Pablo (2011), "Organización delictiva. Bases para su elaboración dogmática en el Derecho penal chileno", Revista Chilena de Derecho, vol. 38, n 2, pp. 279-310, p. 294, quien siguiendo a Kindhäuser, define el peligro abstracto como "la afectación de aquellas condiciones generales de seguridad de las cuales depende la posibilidad de una disposición despreocupada sobre uno o más bienes jurídicos por parte de su(s) titular(es)". Como el mismo autor advierte, con esta definición se hace innecesario el recurso a la "peligrosidad estadística". 
dicos colectivos y que los delitos de peligro concreto protegen preferentemente bienes jurídicos individuales ${ }^{71}$.

Se alude también a que estos delitos tienden a adelantar las barreras de punición en términos discutibles, a diferencia de lo que sucede en el llamado "núcleo clásico" del derecho penal, lo que supone que esta rama del ordenamiento poseería atributos suficientes como para "educar", o "concienciar" a los sujetos acerca de los bienes jurídicos ${ }^{72}$ y, a la par, que la protección exclusiva de bienes jurídicos cede terreno ante esta función, no siendo necesario entonces la verificación, primero, de un verdadero bien jurídico y, segundo, una verdadera afectación de estos, pues se caracterizan estos delitos como aquellos en que el peligro no es elemento del tipo, sino "motivo" del legislador. Si solo constituye el motivo de la incriminación, este puede versar tanto en la tutela de bienes jurídicos como también del castigo de meras desobediencias, desconectadas de un interés concreto y real o sin la necesidad de hacer referencia a él. Con ello no se cumple la exigencia de que el derecho penal constituya la última de las posibilidades de reacción frente a una conducta contraria a derecho, posicionándose, a la inversa, como la primera ${ }^{73}$. De esta forma, al adelantarse las barreras de punición a estados o momentos muy anteriores a la lesión de bienes jurídicos, el derecho penal estaría utilizándose en forma más bien simbólica, todo como parte de un movimiento de criminalizador que responde a criterios de administrativización del derecho penal ${ }^{74}$

También constituirían un potencial atentado al principio de culpabilidad. Dejando en claro que no se requiere de un dolo especial, distinto de las categorías de dolo ya estudiadas, el hecho que la conducta se incrimina no tanto por el acto individual, sino por el peligro ante su ocurrencia indiscriminada, haría requerir que el sujeto se represente dicha posibilidad que escapa por completo de su control, pues este no puede hacerse cargo de lo que otros individuos harán o no harán ${ }^{75}$.

El derecho penal chileno, aún, no abunda en tipos de peligro abstracto, aunque presenta algunos que frecuentemente reportan los pro-

"En general hay que prevenir la asunción de funciones promocionales. Es decir, emplear el Derecho penal para favorecer aquellos intereses, que más que conformar bienes jurídicos propiamente tales, representan la consecución de ciertos objetivos de organización social”. Carnevali Rodríguez (2000) 146.

73 En similar sentido Maldonado (2006) 24.

74 Carnevali Rodríguez, Raúl (2006), "Criterios para la punición de la tentativa en el delito de hurto a establecimientos de autoservicio. Consideraciones político-criminales relativas a la pequeña delincuencia patrimonial", en Política Criminal, n ${ }^{\circ} 1,2006$, pp. 1-17, p. 5; Oliver, Guillermo (2005), "Análisis crítico de las últimas modificaciones legales en materia de hurto-falta". En Revista de Derecho (Valparaíso), XXVI, pp. 295-307, p. 306

75 En este mismo sentido, Carnevali Rodríguez, Raúl (2008). "Derecho penal como ultima ratio. Hacia una política criminal racional”. En Ius et Praxis, 1, pp. 13 a 48, p. 35; VARgas Pinto (2007) 93. 
blemas antes planteados, como la conducción de vehículos en estado de ebriedad $^{76}$. Sin embargo, es posible que su empleo tienda a aumentar en la medida en que nuestro país comience a experimentar los problemas propios del desarrollo económico e industrial, es decir, aquellos que pertenecen a la esfera del derecho penal del riesgo.

\section{2) Peligro abstracto $V / S$ PRincipio de OfENSividad. BREVE REFERENCIA A LA JURISPRUDENCIA DE LA CORTE COSTITUZIONALE Y EL TRIBUNAL CONSTITUCIONAL}

\subsection{1) El caso italiano: desde la ofensividad a la racionalidad}

A pesar de la fuerza expresiva y autoridad de sus representantes, resulta paradigmático que el principio de ofensividad, al menos en su versión "fuerte", no haya jamás sido llamada en causa por la consulta para declarar la inconstitucionalidad de un precepto. Es más, es posible afirmar que, salvo muy contadas excepciones, el principio no ha formado parte de las decisiones de la Corte Constitucional, y si lo ha sido en la letra, ha resultado o ser una versión débil de este o confundido en otros principios, especialmente los de racionalidad y proporción ${ }^{77}$. Resulta una paradoja, pues, mientras otros ordenamientos constitucionales prevén principios generales para la resolución de conflictos de constitucionalidad en la legislación (especialmente el de proporcionalidad), la Corte Constitucional italiana tenía a su disposición un aparato teórico diseñado expresamente para la resolución de una parte importante de posibles conflictos penales ${ }^{78}$.

Las razones que explican esta paradoja pueden ser variadas, desde las expresamente políticas -el temor de una intromisión excesiva en cuestiones que se entienden formar parte de la discrecionalidad del legislador ${ }^{79}$

76 Véase Cabezas, Carlos (2010). "Los delitos de conducción bajo la ingesta del alcohol o sustancias estupefacientes como delitos de peligro". En Revista de Derecho (Valparaíso), n XXXIV, pp. 227-280.

77 Son estas las conclusiones a las que llega Belfiore, Elio (2005). Giudice delle leggi e diritto penale, Milano: Giuffrè, p. 225; Oliver (2005) 305

78 En este sentido Manes (2005) 210, quien señala que "el principio de legalidad (...), el principio de personalidad de la responsabilidad penal y de culpabilidad, el principio de ofensividad -y quizás el mismo principio de subsidiariedad- en el ámbito de la teoría constitucionalmente orientada, eran ya originariamente ideados, o al menos hipotizados, como principios premunidos de fuerza demostrativa, es decir -como se ha señalado-, como normas capaces de fundar una declaración de ilegitimidad constitucional teniendo como objeto una disposición con ellos contrastante, y no pensados solo como principios argumentativos (u orientativos o de mera dirección política) para el legislador, en perspectiva únicamente orientada a una intervención de lege ferenda".

79 Escapan a esta razón los pocos delitos que progresivamente fueron declarados inconstitucionales por la Corte y que decían relación con puniciones de sesgo autoritario que, al ser dictadas antes de la Constitución republicana de 1948, castigaban conductas que luego de la II Guerra Mundial fueron consideradas derechos, como el caso de la huelga por motivos 
-como técnicas- es el caso de los delitos de peligro abstracto, los cuales, en perenne conflicto con el principio de ofensividad son considerados irrenunciables en ciertos sectores del ordenamiento ${ }^{80}$. Como hemos indicado previamente, esta categoría de ilícito resulta un buen banco de prueba de la efectividad práctica del principio, pues, como hemos adelantado, al menos su versión fuerte predica su expulsión del ordenamiento jurídico al convertirse en un potencial atentado contra él.

$\mathrm{Y}$, sin embargo, no ha sido así o, mejor dicho, no ha sido precisamente así. La Corte Constitucional, sobre el particular ha defendido el recurso al peligro presunto ya en 1974, a propósito de la incriminación del delito de incendio del artículo 423 inciso primero del CP llamando en causa la racionalidad ${ }^{81}$. Similar aproximación se presenta en el caso de la presunta ilegitimidad constitucional de la posesión de pequeńas cantidades de droga, configurada aparentemente como delito de peligro abstracto, refutándose dicha acusación también a través del principio de racionalidad, que debe -y en el caso los jueces consideran se ha presentado- en la libertad de configuración del tipo que funciona como límite del actuar del legislador ${ }^{82}$, siempre que respete en la estructuración del peligro abstracto aparezca fundada en reglas de experiencia orientadas al id quom plerumque accidit, es decir, precisamente, que no aparezca dicha selección

contractuales o en el caso del adulterio o concubinato. En estos casos la intervención, que claramente podía leerse como "política" por parte de la Corte, fue pacíficamente aceptada como parte de sus competencias. Sobre el particular, véase Manes (2005) 213 y ss., quien aclara, de todos modos, que estas decisiones se han basado en otras consideraciones y no en la teoría de los bienes jurídicos constitucionalizados. 214.

80 Tal como hemos visto, entre las muchas razones para una utilización, por decirlo así, sumamente "mesurada" de este principio a propósito de delitos de peligro abstracto o presunto se basa, también, en la propia doctrina que ha ido acomodándose a las exigencias de política criminal que harían de este recurso uno de tipo "irrenunciable". En este mismo sentido MaNES (2005) 290.

81 SCC 286/1974. "No se produce, por tanto, violación del art. 3 de la Constitución reconduciéndose la disciplina diferenciada [entre incendio de cosa ajena, considerado por los recurrentes delito de peligro presunto y el incendio de cosa ajena, delito de peligro concreto, art. 423 inc. 1 y 2, respectivamente] en una no irracional elección legislativa que, además, podría encontrar su justificación en la diversa valoración del comportamiento del sujeto, según que incida sobre cosa ajena o sobre la propia.

82 SCC 333/1991. En este caso, el razonamiento de la Corte ha partido precisamente desde la base del discutible cumplimiento del principio de ofensividad por parte del tipo del art. 71 de la Ley no 685 de 22 de diciembre de 1975. De hecho, la sentencia, en su considerando $9^{\circ}$ señala que la (ir)racionalidad y el principio de ofensividad se hayan estrechamente vinculados, solo que al final concluye que "Las incriminaciones de peligro presunto no son incompatibles, en principio, con las disposiciones constitucionales" y que se le reconoce al legislador "la individualización tanto de la conducta a las cuales vincular una presunción absoluta de peligro como al grado o umbral de peligrosidad a la cual hacer referencia". Respecto a la Sentencia, Tanferna, Mario (1995). "Principio di offensività, reati di pericolo erazionalità della norma incriminatrice”. En Giurisprudenza italiana, I, p. 121-122, afirma que en este caso la Corte admite el principio de ofensividad como un principio doblegable, en neto contraste con la Teoría del bien jurídico constitucionalizado. 
de conductas irracionales o arbitrarias ${ }^{83}$. De hecho, la primera vez que el principio fue utilizado directamente fue solo al inicio del siglo XXI, cuando la Corte declaró ilegítimo el inciso segundo del art. $688 \mathrm{CP}$, el cual castigaba con pena privativa de libertad a quien era sorprendido en estado de ebriedad si ya anteriormente había sido condenado por delito doloso contra la vida o la incolumidad personal ${ }^{84}$, en una interesante perspectiva orientada a la incompatibilidad del principio de ofensividad con delitos donde la subjetividad del agente reemplace la necesaria lesión o puesta en peligro de un bien, como sucedía con la agravación de la penalidad del ebrio sorprendido por el solo hecho de ser reincidente. Esta perspectiva ha regresado recientemente en las decisiones de la Corte, en particular la sentencia 249/2010, la cual declara ilegítimo frente a la Constitución la agravante dispuesta por el art. $61 \mathrm{n} .11$ bis del CP, esto es, el hecho de ser el agente un "ilegal", parte del "pachetto sicurezza" del 2008 en la cual el gobierno de turno buscaba luchar contra el extendido fenómeno de la inmigración ilegal a través del derecho penal. La sentencia, a decir de la doctrina ${ }^{85}$, resulta ser una confirmación de la dirección de la Corte que ha convertido el principio de racionalidad en un principio "asimétrico, plural, compuesto, a veces moldeado sobre las peculiares instancias en cuestión en la materia objeto de la valoración" 86 .

El segundo camino por el cual el principio de ofensividad ha venido siendo colocado, es el de "canon hermenéutico unánimemente aceptado", es decir, como explica el mayor monografista de la materia en Italia, como herramienta "tal de imponer al juez la tarea de comprobar hic et nunc que el comportamiento abstractamente peligroso en la descripción del legislador haya alcanzado un minimum de ofensividad en el tipo concretamente verificado" 87 . La sentencia principal a este respecto decía relación con la detención de pequeñas cantidades de explosivo, conducta retenida por el juez de la instancia como desigualmente castigada (con una pena

83 En este sentido, Manes (2005) 235. A propósito de la discrecionalidad del legislador, otro ejemplo interesante se encuentra en la sentencia 370/1996, la cual rechaza el recurso por ilegitimidad constitucional del art. 707 CP que castiga un típico delito de sospecha, la tenencia injustificada de llaves alteradas o ganzúas si el sujeto previamente había sido sancionado por delito determinado por el lucro o contra el patrimonio, haciendo pesar, nuevamente, la legitimidad del tipo penal en la no irracionalidad de la disposición del legislador.

SCC no 354/2002: "la norma punitiva, más allá de la intención del legislador, termina por castigar no tanto la ebriedad en sí (...) sino una cualidad personal del sujeto”. A propósito de esta sentencia, Silvani, Simona (2002). "Definitivamente estromessa dal sistema penale l'ubriachezza manifesta”. En Giurisprudenza Costituzionale, fasc. 4, pp. 2659-2674.

Véase Manes, Vittorio (2011). "I recenti tracciati della giurisprudenza costituzionale in materia di offensività e ragionevolezza”. En Diritto penale contemporáneo. Ottobre, pp. 1-17. Disponible en http://www.penalecontemporaneo.it/upload/Manes\%20off\%20rag.pdf [fecha de visita 5 de julio de 2012].

86 Manes (2011) 17.

87 MANEs (2005) 236. 
más severa) que otros delitos de mayor gravedad. En este caso, y como la Corte Constitucional ha hecho habitualmente, sin afirmar derechamente el principio de ofensividad constitucionalizado, otorga esta tarea de control al juez, llamando en causa el art. 49 del CP, declarando "establecer si una mínima cantidad de explosivo sea, en el caso concreto, inidónea para ofender los bienes tutelados de la normativa en discusión: y para llegar a dicha conclusión, el juez no puede sino considerar todos los instrumentos hermenéuticos que todo el sistema ofrece" 88 .

En conclusión: el principio de ofensividad, a pesar de su atormentada historia y de las críticas y resquemores que ha despertado, parece todavía estar vivo en el sistema penal italiano, pero no con capacidad demostrativa directa, sino a través de principios diversos como el de racionalidad $^{89}$. Es decir, de la rigidez original, el principio ha desarrollado una flexibilidad que en ocasiones lo ha hecho desvanecer, pero que en otras, más numerosas, ha revelado ser de una utilidad -quizás menor de la que sus creadores esperaban ${ }^{90}-$, pero aun plena de desarrollos y direcciones interesantes que justifican una profundización de sus principales líneas teóricas ${ }^{91}$.

\subsection{2) El caso chileno: el peligro abstracto interpretado como peligro concreto}

La breve historia de la Jurisprudencia del Tribunal Constitucional chileno en materia de inaplicabilidad de normas legales por embestir con

88 SCC 62/1986. El reclamo a la idoneidad de los actos ex art. 49 CP, pareciera remitirse, como afirma una parte de la doctrina al juicio pronóstico propio de los delitos de peligro concreto. Nos remitimos a las perplejidades y dudas que la doctrina italiana exhibe sobre el particular, supra 2.2.1. Por otra parte, advierte Fiandaca (2003) 154, que este mandato dirigido al juez - control en concreto de la peligrosidad en abstracto- tiene un reverso de la medalla: esta operación interpretativa termina con sustituir una declaración de inconstitucionalidad de la norma.

89 En todo caso, esta actitud de la Corte ha sido objeto de críticas: "Se puede subrayar desde ya que la falta de rigor de la jurisprudencia constitucional en cuanto a la incardinación de las argumentaciones a los específicos principios cardinales de la $<<$ materia penal $>>$ (reserva de ley, taxatividad, ofensividad, culpabilidad, etc.) a favor de la panacea ofrecida por el criterio de la racionalidad (y/o igualdad y/o proporcionalidad) se revela tanto más riesgosa cuanto más las <<elecciones >> de la Corte se alejen (o puedan alejarse) de aquellas del órgano $<<$ depositario $>>$ del poder legislativo, alteren el equilibrio de los poderes peculiares del estado de derecho". Belfiore (2005) 227.

90 Es decir, una actitud que parece obedecer a la idea de un equilibrio entre tecnicismo (es decir, haciendo caso omiso de los principios del derecho penal) y el principalismo (orientación que resuelve los conflictos solo mediante ellos). Sobre este punto Gargani (2005) 190, señala que esta última postura puede dar lugar a la adopción de criterios hermenéuticos más laxos y blandos o en cambio a la tendencia a descuidar la voluntad del legislador histórico y la letra de la ley".

91 Son estas las conclusiones de los autores que se han ocupado del tema: Manes (2005) 242; Palazzo (1998) 361; Valenti (2006) 292. 
disposiciones constitucionales -en rigor, iniciado solo en 2005-, cuenta con pocas sentencias en materia; sin embargo, ellas no dejan de ser interesantes, aun cuando sea necesario reconocer que el nivel argumentativo que presentan es más bien escaso ${ }^{92}$. El camino se inaugura con la sentencia 739/2007 de inaplicabilidad del precepto del CP, art. 292, que, como sabemos, castiga el delito de asociación ilícita. El recurso fue interpuesto alegando la incompatibilidad de las presunciones de responsabilidad en materia penal, acusando, por tanto, a la disposición en comento de contener una presunción de responsabilidad, pues la asociación ilícita es un delito que existe "por el solo hecho de organizarse", es decir, un delito de peligro abstracto. La Corte rechaza el recurso y en el particular afirma que, aunque el principio de lesividad no se encuentra expresamente consagrado en la Constitución, es un principio del derecho penal que exige la presencia de un bien jurídico determinado y "realmente afectado" para medir luego la intensidad de la ofensa y, consecuentemente, la sanción (considerando 15). Luego, más adelante, reconoce que la aplicación de este principio puede producir la paradoja de deslegitimar un delito que protege bienes jurídicos de importancia, como la vida o la seguridad. La solución estaría en "interpretar el precepto guiándose por la presunción de legitimidad que emana de los actos del legislador, concordándola con los principios y valores constitucionales, parece razonable y coherente con la protección del orden público y el recto ejercicio del derecho de asociación que la Constitución consagra" y, por tanto, "Que, en la especie, tal objetivo se logra estimando como un elemento del tipo su peligrosidad concreta y, por ende, dicha circunstancia debe ser acreditada”.

El pronunciamiento de la Corte, más allá de que compartimos ciertos puntos, no deja de ser sorprendente, pues, como hemos visto, de un lado, resuelve el problema con un principio que se resiste a declararlo constitucionalizado (pero que parecería ingresar por vía de la racionalidad) y porque en Chile, como hemos visto, se replican los intensos problemas doctrinales acerca de esta categoría. Además, el Tribunal no se hace cargo de una posible crítica, que consiste en el eventual conflicto con el principio de legalidad y tampoco aclara si se trataría de una inversión de la carga de la prueba, es decir, si es el imputado quien debiese probar la inofensividad de su conducta o, por el contrario, debe ser determinada por el órgano acusador.

La segunda sentencia en la cual el Tribunal ha lidiado con el tema de la ofensividad es la 993-07, de 13 de mayo de 2008, que decía relación con un recurso de inaplicabilidad del art. 4 de la Ley 20.000, nuevamente

92 Con todo, hasta el momento suelen ser de un interés mayor por la cantidad y calidad de los argumentos las opiniones de disenso. 
fundada en una supuesta presunción de responsabilidad. El Tribunal concluye, en este caso, que no se trata de un delito de peligro abstracto, sino concreto: "Resulta inequívoco, entonces, que la conducta incriminada es la tenencia de las drogas prohibidas no destinadas al uso o consumo personal o con el propósito de traficar a cualquier título, quedando patente el bien jurídico protegido. En consecuencia, se trata de una peligrosidad concreta y que, por ende, debe ser acreditada en el proceso".

Estas son las dos sentencias que, por el momento, se han ocupado del problema del principio de ofensividad directamente respecto de los delitos de peligro. De lo fallado, se desprende que el Tribunal entiende que el principio de ofensividad, si bien carece de rango constitucional per se, formaría parte de la racionalidad. En estos casos aún no hace uso, al menos explícitamente, del criterio de proporcionalidad, ampliamente aceptado en la doctrina española y alemana, el cual llamaría en causa al principio de ofensividad o lesividad ${ }^{93}$.

De todos modos no son las únicas sentencias de interés sobre la ofensividad. El Tribunal ha tenido la oportunidad de resolver la compleja cuestión de la legitimidad constitucional del art. 450 inc. $1^{\circ}$ del $\mathrm{CP}^{94}$, el cual equipara las penas de la tentativa con las de la consumación en el delito de robo con violencia o intimidación y el robo con fuerza en las cosas ${ }^{95}$. Así, su considerando décimo octavo señala expresamente "que la existencia de un trato diferente para una cierta categoría de delitos no es suficiente para concluir que ello es contrario a la Carta Fundamental, pues esta no prohíbe establecer diferencias, sino que hacerlo arbitrariamente, esto es, careciendo de fundamento

93 Para Fernández Cruz (2010) 67, por ejemplo, el principio de ofensividad pertenece o forma parte del juicio de proporcionalidad, el cual de esta forma estaría implícitamente constitucionalizado: "A la vista de la estructura y contenido del principio de proporcionalidad en sentido amplio, los principios y límites al ius puniendi pueden considerarse como normas adscritas a derechos fundamentales o pueden formar parte del propio el juicio constitucional de proporcionalidad. Como normas adscritas, por ejemplo, la doctrina nacional ha vinculado el principio de culpabilidad penal a varios preceptos constitucionales (arts. 1 , incs. $1^{\circ}$ y $4^{\circ}, \mathrm{y}$ 19. $\mathrm{N}^{\circ} 3$, inc. 6 CPR77). Como parte del contenido del juicio constitucional de proporcionalidad, claramente, podemos incluir los principios de lesividad y necesidad" (p. 73). En un sentido distinto se decanta Fuentes Cubillos, Hernán (2008), "El principio de proporcionalidad en derecho penal. Algunas consideraciones acerca de su concretización en el ámbito de la individualización de la pena”, en Ius et Praxis, ańo 14, n² 2, pp. 15-42, p. 28, para quien se trataría de principios independientes, aun cuando luego, en página 39, agrupa dentro de los criterios de la proporcionalidad concreta (esto es, aquella que dice relación con la individualización judicial de la pena) "la específica lesión o el grado de peligro al cual fue expuesto el bien jurídico, la densidad del daño efectivamente causado". Con todo, el autor se preocupa en aclarar que la proporcionalidad concreta no es suficiente fundamento para un juicio de constitucionalidad que siempre se refiere a la proporcionalidad en abstracto.

$94 \quad$ STC n ${ }^{\circ} 825 / 2008$.

95 Se trata de un viejo reclamo doctrinal la desaparición de esta equiparación. Ver, por todos, Politoff Matus y Ramírez (2006) 380. En todo caso, me merece dudas su posición respecto, precisamente, a la proporcionalidad. Ver también misma página, nota 4. 
razonable que pueda justificarlas”. Luego, en el considerando vigésimo primero, sostienen que "a esta Magistratura no le corresponde sustituir el juicio propio del legislador ni juzgar la sabiduría o mérito de los instrumentos que emplea, incluso si ellos conllevan diferencias, a condición de que estos instrumentos diferenciadores se presenten como razonablemente idóneos para alcanzar fines constitucionalmente lícitos y se dé la proporcionalidad". Y respecto de ella, el considerando vigésimo segundo señala que "En virtud de su supresión, los responsables de delitos que hayan quedado en grado de tentados o frustrados recibirán las mismas penas asignadas por la ley a los respectivos delitos, solo que sin beneficiarse de las disminuciones que la ley asigna, en general, a los responsables de otros delitos no consumados. Imponer este gravamen y trato diverso no puede considerarse tan desproporcionado al logro del fin de prevención general asignado a las penas como para calificarlo de arbitrario o carente de razonabilidad". Como es evidente, los ministros de la mayoría no hablan de proporcionalidad (ni menos de lesividad u ofensividad), sino que solo se refieren a la racionalidad de la elección del legislador en materia penal.

Otra sentencia que indirectamente dice relación con el principio de ofensividad -o que a lo menos no estuvo presente en los argumentos del fallo- es aquella que se pronunció acerca de la constitucionalidad del delito consagrado en el artículo $365 \mathrm{CP}$, que castiga la sodomía consentida entre varones cuando la "víctima" sea un varón menor de 18 años pero mayor de 14 y sin que se presenten las circunstancias del estupro o la violación ${ }^{96}$. Como es lógico, el principal argumento del recurrente fue una evidente infracción al principio de igualdad, puesto que se sanciona una conducta que con sujetos diversos (un hombre y una mujer, dos mujeres, o el menor de edad varón que penetra al varón adulto) no se consuma delito alguno. El tribunal desestima el recurso y llama en causa el bien jurídico solo para afirmar que detrás de la norma impugnada existe uno (el desarrollo inalterado de la sexualidad del menor), sin decir palabra acerca de la grosera desigualdad expresada en la norma ${ }^{97}$.

A este punto, respecto de la aún joven jurisprudencia constitucional penal chilena, pueden compartirse las conclusiones a las que otros autores han llegado sobre el particular, es decir, que existe un manejo más bien escaso de los recursos argumentativos derivados del principio de propor-

\footnotetext{
$96 \quad$ STC n ${ }^{\circ} 1683 / 2011$.

97 Resume estas críticas Cisternas Véliz, Luciano (2011). “Comentario al fallo del tribunal constitucional rol $n^{\circ} 1683-2010$, sobre el requerimiento de inaplicabilidad por inconstitucionalidad del art. 365 c.p.”. En Revista de Derechos fundamentales, n 5, pp. 181-188. Hay que hacer presente que los votos de disidencia son más interesantes y acusan a la norma de ser directamente "homofóbica".
} 
cionalidad $^{98}$; sin embargo, sorprende que la Corte se base en el principio de lesividad, aun cuando reconoce que no está constitucionalizado, aunque debe admitirse que lo ha hecho en términos netamente argumentativos, conectándolo con la racionalidad (es decir, no como un principio independiente). La sentencia más paradigmática sobre el particular es la 739/2009, donde la Corte parece asumir algunas de las características de la denominada "ofensividad débil" utilizada también por la Corte Constitucional italiana no para declarar inaplicable un delito de peligro abstracto, sino para reinterpretarlo en clave de peligro concreto.

Uno de los motivos por los cuales el Tribunal chileno puede haber tomado este camino (además de las dudas de constitucionalidad del principio de ofensividad y, luego, su contenido y funciones específicas), es la propia naturaleza del juicio de inaplicabilidad. Como lo ha revelado la doctrina reciente, la naturaleza de este juicio, que busca juzgar inaplicabilidades de la norma y no la ilegitimidad constitucional de la misma, podría inducir a los jueces a un fuerte self restraint ${ }^{99}$, evitando así ser demasiado drásticos en un juicio que no puede, por naturaleza, incidir en la norma en abstracto. Con todo, las dudas que rodean la naturaleza del juicio de inaplicabilidad recomiendan no hipotizar demasiado sobre el particular $^{100}$.

98 Véase, sobre el particular, Lopera Mesa, Gloria (2011). "Principio de proporcionalidad y control constitucional de las leyes penales. Una comparación entre las experiencias de Chile y Colombia”. En Revista de Derecho (Valdivia), vol XXIV, n² 22, diciembre, pp. 113-138, p. 123; Fernández Cruz, (2010) 53.

99 A propósito del self restraint que parece operar en el Tribunal, según VAN Weezel, Alex (2011), La garantía de tipicidad en la jurisprudencia del Tribunal Constitucional, Santiago, AbeledoPerrot, p. 52, la solución sería, al menos para los casos del nullum crimen a los cuales el autor se refiere, "pasa por entender que en ordenamiento jurídico chileno existe el deber de realizar una interpretación conforme a la Constitución de los tipos sancionatorios. Es decir, que la acción de inaplicabilidad por inconstitucionalidad solo está disponible cuando definitivamente no resulta posible una interpretación de la norma que se ajuste a la Carta Fundamental". Sin embargo, se preocupa de aclarar más adelante que para ello "sería preciso que la Magistratura Constitucional, en lugar de realizar ella misma una interpretación de los tipos en términos compatibles con la garantía de tipicidad, entregara a los tribunales ordinarios esa función, limitándose en el extremo a señalar en qué dirección podrían discurrir las alternativas interpretativas compatibles con el principio" (p. 55).

100 Sobre la problemática naturaleza de esta acción, Couso Salas, Javier y Coddou MacmaNUS, Alberto (2010). "La naturaleza jurídica de la acción de inaplicabilidad en la jurisprudencia del Tribunal constitucional: un desafío pendiente". En Estudios constitucionales, n ${ }^{\circ}$, pp. 389-430. Los autores expresan cierta perplejidad ante la naturaleza de la acción, que de todos modos se desprende de las disposiciones de la Carta Fundamental, pues si el control de inaplicabilidad es abstracto y el de inconstitucionalidad es concreto, no se entiende por qué el primero deba ser un requisito de procedencia del segundo (véase p. 397). También VAN WeEzel (2011) 47-48 


\section{4) ConClusiones. Puntos de CONTACTO Y POSIBLE EVOluCión DE LA JURISPRUDENCIA DE LEGITIMIDAD CHILENA}

Las sentencias n ${ }^{\circ} 793 / 2007$ y n $^{\circ} 993 / 2007$ del Tribunal Constitucional chileno aún están lejos de poder señalarse como fallos paradigmáticos acerca del principio de ofensividad en Chile. Las carencias argumentativas ya denunciadas a propósito de otras decisiones y el neto contraste que exhiben con la doctrina penal más reciente nos permiten muy verosímilmente esperar un futuro cambio de dirección, especialmente si la conformación del Tribunal sigue siendo preferentemente "académica".

La experiencia italiana, más antigua y por ende rica en argumentos, de todos modos nos presenta la historia de un principio del cual se esperaba un gran rendimiento práctico y que, sin embargo, ha terminado por ser absorbido (quizás justificadamente) por otros principios. Es cierto que la Corte Constitucional raramente ha empleado la ofensividad como parámetro para la valoración de las normas legales y cuando se decide a utilizarlo lo hace a través de un expediente oblicuo, incardinando la lesividad como parte de un principio de mayor alcance, reduciendo de este modo sus efectos. En este delicado balance, parece que la ofensividad tiende a funcionar mejor

Tanto el ordenamiento italiano como el chileno reconocen la existencia del principio de ofensividad o lesividad, aunque, como hemos visto, con dimensiones, roles y funciones diversos. Mientras la doctrina italiana tiende a observarlo como un principio constitucionalizado -sin perjuicio de las notables diferencias de configuración entre los distintos autores-, la doctrina chilena es más dubitativa sobre el particular. Ello puede responder, además, a que la ciencia penal chilena, al menos tradicionalmente, tiende a observar en la Constitución más un límite que una norma fundante de principios penales ${ }^{101}$.

Las diferencias más relevantes, con todo, tienen que ver con las distintas funciones asignadas. La doctrina italiana ha demostrado una evolución que va desde una versión fuerte del principio, el cual podía -y se esperaba- que operase independientemente, a una más débil y flexible, evolución que coincide con el debilitamiento del concepto de bien jurídico y que presenta su paralelo en el desarrollo de la jurisprudencia constitucional. En Chile, se tiende a ver el principio en doctrina, más allá de su constitucionalización, como un principio legitimador, limitativo pero siempre en compañía de o al interior de otros principios, especialmente el de proporcionalidad ${ }^{102}$. Sin embargo, parece claro que en nuestro país

\footnotetext{
101 Sobre este punto, véase Durán Migliardi (2011) 145.

102 Para Fuentes Cruz (2010), 67, es preferible la utilización del juicio de proporcionalidad por su potencia discursiva, porque permite una sistematización de los principios y límites del ius puniendi desde la teoría de los derechos fundamentales y porque por primera vez se
} 
una eventual versión fuerte de este principio no ha sido aceptada en doctrina.

Respecto a la jurisprudencia constitucional, las cosas son algo diversas. En Italia, a pesar de tener a la mano este recurso demostrativo, la Corte jamás lo ha usado de esta forma -al menos en lo que se refiere a casos de adelantamiento del umbral de punición, tema en el que nos hemos concentrado- y tiende a incardinar la ofensividad como parte de la racionalidad que debe animar las elecciones del legislador. La temprana defensa de los discutibles delitos de peligro presunto es una demostración que tiende a utilizar el principio de exclusiva protección de bienes jurídicos en una versión débil, argumentativa, lo que, en todo caso, no debe llevar a la apresurada conclusión que la ofensividad ha perdido definitivamente importancia en el ordenamiento italiano; por el contrario, esta "resurrección" del principio, aun en términos algo diversos de su originaria concepción, le ha permitido desarrollarse en áreas donde parecía menos "apto" como en el caso de la ilegitimidad de incriminaciones basadas en criterios meramente subjetivos.

La jurisprudencia constitucional chilena, aún joven, en cambio, parece sentirse bastante más cómoda utilizando la ofensividad que el juicio de proporción, preferido por la doctrina, como hemos visto. Si bien los argumentos son más bien escasos, en la visión de los ministros del Tribunal la ofensividad no parece suficiente para fundar directamente una inaplicabilidad -y consecuentemente una eventual inconstitucionalidad-, pero forma parte importante del criterio de racionalidad que debe asistir al legislador al momento de la creación de la norma. Es más, el Tribunal, siempre desde el punto de vista hermenéutico-argumentativo, es proclive a la interpretación de los delitos de peligro abstracto como delitos de peligro concreto -salvando así el principio de ofensividad y el tipo penal impugnado-, lo que la acerca a la experiencia italiana en este sentido. Por cierto, no es posible adelantar un pronóstico referente a si esta línea jurisprudencial se mantendrá en el tiempo y es probable que no: pero ya resulta interesante notar cómo dos experiencias disímiles históricamente presentan tan acusados puntos de contacto. Nos atrevemos a especular que ello puede deberse a la fuerza conceptual del principio de ofensividad por su neta raigambre liberal orientada a la formación de un derecho penal objetivo, reduciendo al máximo los elementos subjetivizantes, se adapta perfectamente a sistemas como el nuestro. Los problemas de la ofensividad, con todo, se presentan en concreto, es decir, cuando el principio debe confrontarse con tipos construidos, en parte sobre la base de criterios de objetividad más débiles, como es el caso de los delitos de peligro abstracto

otorga una efectiva virtualidad práctica a los límites del ius puniendi, entre ellos, el principio de lesividad. 
o presunto. En ellos, el principio parece necesitar el auxilio orientaciones político-criminales que pueden incardinarse en otros principios o juicios, como el de racionalidad o proporcionalidad.

Con todo, es necesario dirigir al Tribunal Constitucional chileno críticas similares a las que ha sufrido su homóloga italiana en lo que se refiere a la utilización del concepto de bien jurídico y al propio principio de proporcionalidad. La inserción de un requisito que no comparece en el tipo (en este caso la verificación de un peligro concreto en la asociación ilícita) presenta problemas de no poca importancia. De hecho, como se ha señalado en la doctrina italiana, una declaración del tipo, esconde, en realidad, una declaración de inaplicabilidad, sorteada gracias al recurso hermenéutico. Ello coloca en los jueces del fondo la pesada y quizás más inconstitucional obligación de interpretar tipos penales de peligro abstracto como delitos de peligro concreto, lo que despierta razonables perplejidades en sede de legalidad ${ }^{103}$.

Por otra parte, la utilización por parte del Tribunal del bien jurídico ilustra perfectamente como este concepto puede ser declinado en modos diversos y para justificar opciones legislativas en absoluto reñidas con su finalidad originaria (teóricamente: limitar el ius puniendi). En las sentencias que declararon la aplicabilidad de los arts. $450 \mathrm{n}^{\circ} 3$ y $365 \mathrm{CP}$, el Tribunal se basó en la existencia de bienes jurídicos tutelados para justificar, en un caso, el adelantamiento del umbral de punibilidad y la incriminación de una conducta que, por lo menos, atenta flagrantemente contra el principio de igualdad, ignorando los argumentos de las posiciones de minoría que en uno y otro caso sí se valieron del concepto de bien jurídico en clave crítica. Con ello se anulan los pretendidos efectos limitativos del ius puniendi que el bien jurídico contiene.

En suma: aún tímida y limitadamente, la teoría del bien jurídico y el principio de ofensividad encuentran acogida tanto en la Corte Costituzionale como en el Tribunal Constitucional, pero de un modo flexible que a veces arriesga con diluirse y desaparecer fagocitados por otros instrumentos. Con todo, en ambas experiencias la herencia de la necesaria lesividad, a pesar de las críticas y dificultades que acarrea, continúa siendo

103 Otra solución aportada en Chile es continuar considerando la asociación ilícita como delito de peligro abstracto, el cual exige la "peligrosidad de la conducta" por lo que se excluiría la verificación del tipo si se probase que "aquella quedó apartada de antemano en el caso concreto": Carnevali Rodríguez, Raúl y Fuentes, Hernán (2008). "Informe jurídico sobre la eventual aplicación del delito de asociación ilícita establecido en el art. 16 de la ley $\mathrm{N}^{\circ}$ 20.000". En Política Criminal, n 6, pp. 1-10, p. 3. Para una crítica a esta posición que centra en la peligrosidad de la conducta la clave de lectura de los delitos de peligro abstracto Cabezas, Carlos (2010). "Los delitos de conducción bajo la ingesta del alcohol o sustancias estupefacientes como delitos de peligro". En Revista de Derecho (Valparaíso), n XXXIV, pp. 227-280, p. 252. A propósito de una posible violación del principio de legalidad, véase supra, nota no 82 . 
una herramienta utilizada para contrarrestar la irracionalidad del legislador contemporáneo. De cómo deba funcionar en el futuro depende, al menos en Chile, de un desarrollo científico y jurisprudencial mayor que permita determinar con claridad los límites de cada bien jurídico (con la intención que la noción recupere, al menos en parte, la capacidad crítica que debiese tener) y las consecuencias del principio de ofensividad, especialmente la delicada cuestión de su constitucionalidad.

\section{Bibliografía CITADA}

- Angioni, Francesco (1983). Contenuto e funzione del concetto di bene giuridico, Milano: Giuffrè.

- Angioni, Francesco (1984). Il pericolo come elemento della fattispecie penale: la struttura oggettiva. Segunda edición, Milano: Giuffré

- Belfiore, Elio (2005). Giudice delle leggi e diritto penale, Milano: Giuffrè.

- Bettiol, Giuseppe (1995). El problema penal. Traducción de José Luis Guzmán Dalbora. Buenos Aires: Hammurabi.

- Bricola, Franco (1997) “Teoría generale del reato", en Canestrari, S. y Melchionda, A: Scritti di diritto penale. Milano: Giuffrè, vol. 1 pp. 539-820.

- Bustos Ramírez, Juan y Hormazábal Malarée, Hernán (1997). Lecciones de Derecho penal, Madrid: Trotta, tomo I y tomo II.

- Cabezas, Carlos (2010). "Los delitos de conducción bajo la ingesta del alcohol o sustancias estupefacientes como delitos de peligro". En Revista de Derecho (Valparaíso), n XXXIV, pp. 227-280.

- Canestrari, Stefano (1991). "Reati di pericolo". En Enciclopedia Giuridica Treccani, t. XXVL, pp. 1-10.

- Carnevali Rodríguez, Raúl (2000) "Algunas reflexiones en relación a la protección penal de los bienes jurídicos supraindividuales”. En Revista Chilena de Derecho, vol n²7, n 1, pp. 135 a 153.

- Carnevali Rodríguez, Raúl (2006), "Criterios para la punición de la tentativa en el delito de hurto a establecimientos de autoservicio. Consideraciones político-criminales relativas a la pequeña delincuencia patrimonial”, en Politica Criminal, $\mathrm{n}^{\circ}$ 1, 2006, pp. $1-17$.

- Carnevali Rodríguez, Raúl (2008). "Derecho penal como ultima ratio. Hacia una política criminal racional". En Ius et Praxis, 1 pp. 13 a 48 .

- Carnevali Rodríguez, Raúl y Fuentes, Hernán (2008). "Informe jurídico sobre la eventual aplicación del delito de asociación ilícita 
establecido en el art. 16 de la Ley N ${ }^{\circ} 20.000 "$. En Politica Criminal, $\mathrm{n}^{\circ}$ 6, pp. 1-10.

- Carnevali Rodríguez, Raúl, (2008). "Derecho penal como ultima ratio. Hacia una política criminal racional". En Ius et Praxis, $n^{\circ} 1$, año 14 , pp. 13 a 48.

- Catenacci, Mauro (2006). "I reati di pericolo presunto fra diritto e processo penale". En Dolcini, E. y Paliero, C.E. (ed.), Studi in onore di Giorgio Marinucci, Milano: Giuffrè, pp. 1415-1442.

- Cisternas Véliz, Luciano (2011). "Comentario al fallo del tribunal constitucional rol $\mathrm{n}^{\circ} 1683-2010$, sobre el requerimiento de inaplicabilidad por inconstitucionalidad del art. 365 c.p.". En Revista de Derechos fundamentales, $\mathrm{n}^{\circ}$ 5, pp. 181-188.

- Couso Salas, Javier y Coddou Macmanus, Alberto (2010). "La naturaleza jurídica de la acción de inaplicabilidad en la jurisprudencia del Tribunal constitucional: un desafío pendiente". En Estudios constitucionales, $\mathrm{n}^{\circ}$ 2, pp. 389-430.

- Cury Urzúa, Enrique (2005) Derecho penal parte general. Santiago: Ediciones Universidad Católica de Chile.

- Del Río, Raimundo (1945), Explicaciones de Derecho penal, dos tomos, Santiago: Nascimento.

- Donini, Masimo, (1996) Teoria generale del reato. Una Introduzione, Padova: Cedam, 1996.

- Donini, Massimo (2004) Il volto attuale dellillecito penale, Milano: Giuffrè, 2004.

- Durán Migliardi, Mario (2011) "Constitución y legitimación de la pena. Apuntes teleológicos sobre el rol de la Constitución en el sistema penal". 142-162. En Politica criminal, n 11, junio 2011, pp.

- Etcheberry, Alfredo (1997). Derecho penal. Tercera edición. Santiago: Editorial Jurídica de Chile, vol. I.

- Fernández Cruz, José Ángel (2010). "El juicio constitucional de proporcionalidad de las leyes penales. ¿La legitimación democrática como medio para mitigar su inherente irracionalidad?". En Revista de Derecho U. Católica del Norte, $\mathrm{n}^{\circ}$ 1, pp. 51-99.

- Fiandaca, Giovanni (1984), "La tipicizzazione del pericolo". Dei delitti e delle pene (3), 441-472.

- Fiandaca, Giovanni (2003). "Nessun reato senza offesa". En Fiandaca, G. y De Chiara, G. Una introduzione al sistema penale. Napoli: Jovene, pp. 103-157.

- Fiandaca, Giovanni; Musco, Enzo (2001) Diritto penale, parte generale. Quarta edizione, Bologna: Zanichelli.

- Fiore, Carlo (1994). "Il principio di offensività". L'Indice penale, fasc. 2, pp. 275-288. 
- Fuentes Cubillos, Hernán (2008), “El principio de proporcionalidad en derecho penal. Algunas consideraciones acerca de su concretización en el ámbito de la individualización de la pena” en Ius et praxis, ańo 14, n ${ }^{\circ}$ 2, pp. 15-42.

- Gargani, Alberto (2005). Il danno qualificato dal pericolo. Torino, Giappichelli.

- Garrido Montt, Mario (2003). Derecho penal. Tercera edición. Santiago: Editorial Jurídica de Chile, tomo II.

- Grasso, Giovanni (1986), "L'anticipazione della tutela penale; i reati di pericolo e i reati di attentato". Rivista italiana di diritto e procedura penale, (3), 689-728.

- Guzmán Dalbora, José Luis (2001). El delito de amenazas, Santiago: LexisNexis.

- Lopera Mesa, Gloria (2011). "Principio de proporcionalidad y control constitucional de las leyes penales. Una comparación entre las experiencias de Chile y Colombia”. En Revista de Derecho (Valdivia), vol XXIV, n² 22, diciembre, pp. 113-138.

- Maldonado Francisco (2006) "Reflexiones sobre las técnicas de tipificación de los llamados delitos de peligro en el moderno Derecho penal". En Revista de Estudios de la Justicia, 7, pp. 23-63.

- Mañalich, Juan Pablo (2004). "La tentativa y el desestimiento en el derecho penal. Algunas consideraciones conceptuales”. En Revista de estudios de la Justicia, $\mathrm{n}^{\circ}$ 4, pp. 137-175.

- Mañalich, Juan Pablo (2011), "Organización delictiva. Bases para su elaboración dogmática en el Derecho penal chileno", Revista Chilena de Derecho, vol. 38, n 2, pp. 279-310.

- Manes, Vittorio (2005) Il principio di offensività nel diritto penale, Torino: Giappichelli, 2005.

- Manes, Vittorio (2011). "I recenti tracciati della giurisprudenza costituzionale in materia di offensività e ragionevolezza”. En Diritto penale contemporáneo. Ottobre, pp. 1-17. Disponible en http://www. penalecontemporaneo.it/upload/Manes\%20off\%20rag.pdf [fecha de visita 5 de julio de 2012].

- Mantovani, Ferrando (2009). Diritto penale, parte generale. Padova: Cedam.

- Marinucci, Giorgio y Dolcini, Emilio (2009). Manuale di diritto penale. Parte Generale. Terza edizione. Milano: Giuffrè.

- Matus Acuña, Jean Pierre (1996), "Sobre la necesidad constitucional de la existencia de un bien jurídico a proteger por los tipos penales". En Revista Universum, Talca n ${ }^{\circ} 11$, pp. 123 a 132.

- Mazzacuva, Nicola (2006), "Diritto penale e costituzione", en Insolera G., Mazzacuva N., Pavarini, M., Zanotti, M. Introduzione al sistema penale. Terza edizione. Torino: Giappichelli, pp. 83-125. 
- Mera, Jorge (1998). Derechos humanos en el Derecho penal chileno. Santiago: ConoSur.

- Moccia, Sergio (2003). El derecho penal entre ser y valor. Traducción de Antonio Bonnano. Montevideo: BdF.

- Náquira Riveros, Jaime (1998). Derecho penal. Teoría del delito. Santiago: McGraw-Hill, tomo I.

- Novoa Monreal, Eduardo (2005). Curso de Derecho penal chileno. Parte general, Santiago: Jurídica de Chile, tomo I.

- Oliver Calderón, Guillermo (2007). Retroactividad $e$ irretroactividad de las leyes penales. Santiago: Editorial Jurídica de Chile.

- Oliver, Guillermo (2005), "Análisis crítico de las últimas modificaciones legales en materia de hurto-falta". En Revista de Derecho (Valparaiso), XXVI, pp. 295-307.

- Orlandi, Renzo (1997). "Effettività della sanzione penale e pricipi processuali”. En Critica del Diritto, fasc. 4, pp. 212-228.

- Ossandón Widow, María (2009), La Formulación de tipos penales. Valoración critica de los instrumentos de técnica legislativa, Santiago: Jurídica de Chile.

- Padovani, Tulio (2008). Diritto penale, novena edición, Milano: Giuffrè.

- Pagliaro, Antonio (2007) "Il reato". En Grosso, C.F., Padovani, T., Pagliaro, A., Trattato di Diritto penale, Milano, Giuffrè.

- Palazzo, Francesco (1998). "Offensività e ragionevolezza nel controllo di costituzionalità sul contenuto delle leggi penali”. Rivista italiana di diritto e procedura penale, fasc. 2, pp. 350-384.

- Palazzo, Francesco (2008). Corso di Diritto penale, parte generale. Terza edizione. Torino: Giappichelli.

- Parodi Giusino, Manfredi (1990). I Reati di pericolo tra dogmatica e politica criminale. Milano: Giuffrè, p. 144.

- Pelissero, Marco (2008). Pericolosità sociale e doppio binario. Torino: Giappichelli.

- Piña Rochefort, Juan Ignacio (2010). Derecho penal, fundamentos de la responsabilidad. Santiago: AbeledoPerrot.

- Politoff, Sergio; Matus, Jean Pierre y Ramírez, María Cecilia (2004). Lecciones de derecho penal chileno. Parte general. Santiago: Editorial Jurídica de Chile.

- Pulitanò, Domenico (1976). L'errore di diritto nella teoría del reato, Milano: Giuffrè.

- Rettig Espinoza, Mauricio (2009), "Desarrollo previsible de la relación entre la antijuridicidad y la culpabilidad", en Revista de Derecho (Valdivia), vol. XXII, No 2, pp. 185-203. 
- Rivacoba y Rivacoba, Manuel (1999). "Introducción al estudio de los principios cardinales del Derecho penal". En Direito e Ciudadania, año II, n 6 , pp. 57-72.

- Rocco, Arturo (1913) L'oggetto del reato e della tutela giuridica penale. Contributo alle teorie generali del reato e della tutela giuridica penale. Contributo alle teorie generali del reato e della pena. Torino: F.lli Bocca.

- Romano, Mario (2004) Comentario sistematico del Codice penale. Terza edizione. Milano: Giuffré, vol. 1.

- Rosoni, Isabella (2006) "Dalle codificazione preunitarie al códice Rocco", en Insolera G., Mazzacuva N., Pavarini, M., Zanotti., M. Introduzione al sistema penale. Terza edizione. Torino: Giappichelli, pp. 3-31.

- Salcuni, Giandomenico (2007). "Esiguità e reati di pericolo astratto: intorno all'applicabilità dell'art. 34 D.LG. N. 274 del 2000 al reato di guida in stato di ebbrezza". Cassazione penale, n. 07/08, 2901-2911.

- Silvani, Simona (2002). "Definitivamente estromessa dal sistema penale l'ubriachezza manifesta". En Giurisprudenza Costituzionale, fasc. 4, pp. 2659-2674.

- Tanferna, Mario (1995). "Principio di offensività, reati di pericolo erazionalità della norma incriminatrice”. En Giurisprudenza italiana, I, pp. 121-122.

- Valenti, Alessandro (2006) "Principi di materialità e offensività", en Insolera G., Mazzacuva N., Pavarini, M., Zanotti., M. Introduzione al sistema penale. Terza edizione. Torino: Giappichelli.

- Van Weezel, Alex (2011), La garantía de tipicidad en la jurisprudencia del Tribunal Constitucional, Santiago, AbeledoPerrot.

- Vargas Pinto, Tatiana (2007) Delitos de peligro abstracto y resultado. Determinación de la incertidumbre penalmente relevante. Pamplona: Thomson Aranzadi. 